\title{
Chapter 7 \\ Experimental Investigations \\ on Multi-means and Synergistic Prediction for Rockburst
}

\subsection{Introduction}

Rock is a kind of complicated geological material with in-homogeneity, anisotropy and discontinuity (Senseny et al. 1992). Under external force, the mechanic behaviour of rock is relatively complex, and it is difficult to accurately predict rockburst (Cook 1992; Brady 1969). Rockburst can lead to damage of equipment, substantial staff casualties and property losses (Blake and Hedley 2003; He et al. 2010). Thus, it has become important question for scholars and engineers to be able to predict rockburst.

Many scholars had some research on predicting rockburst. Schiavi et al. (2011b) found that the phenomenon of a relatively quiet period appeared before rockburst under uniaxial compression. Carpinteri et al. (2006), Carpinteri and Lacidogna (2008) made testing on concrete, rock and other materials with AE monitoring technology, and the result demonstrated that AE energy accelerates release before rock failure. Wang et al. (2009) carried out a large number of AE tests in laboratory, and suggested that AE relatively quiet period could be regarded as a precursor. Meanwhile, he studied the fluctuation of $b$ value and obtained the precursory characteristic and predicting key point of rockburst (Wang 2014).

Read et al. (1995) analysed AE waveforms from a series of laboratory triaxial-deformation experiments, and explored the features of waveform amplitudes and frequency before and after the peak stress. Benson et al. (2010) found that disordered AE signals were significantly reduced before rock specimen failure. Schiavi et al. (2011a, b, 2013) founded that elastic emissions were different from acoustic emissions, could be detected in a low frequency range (below $15-10 \mathrm{kHz}$ ). He et al. (2015) presented an experimental investigation on the instantaneous strain-type granitic rockbursts, and found that frequencies changed from low value to high values as the load increased. Lu et al. (2012a, b, 2013) demonstrated that the dominant frequency of main shock signal correlate negatively with rockburst intensity. Kukshenko and Elizarov (2015) made AE test on large scale specimens,

C. Wang, Evolution, Monitoring and Predicting Models of Rockburst, 
and analyzed the result using the load/unload response ratio (LURR) theory, found that $Y$ value change of LURR was consistent with that of rock internal damage, and that the value of $Y$ value increased significantly when the integrity of rock samples was destroyed. LURR theory was also applied to evaluate the degree of damage, which provided a new approach to describe rock failure behavior (Shi et al. 1994; Zhang et al. 2013). Some results for earthquake precursor information were obtained, radiation temperatures in the earth's crust were unusually high in the weather satellites observation (Qiang et al. 1990). Before the earthquake, earth satellite images had obvious infrared thermal enhancement phenomenon, which was called "thermal anomaly" (Freund et al. 2007). In the past few decades, the abnormal increase of surface temperature was successfully verified (Genzano et al. 2007; Saraf et al. 2008). In laboratory tests, abnormal infrared radiation was used as precursor of rock failure on the Similarity simulation experiment of earthquake (Rawat et al. 2011; Naiguang et al. 1998; Geng et al. 1992).

The new inter-discipline of remote sensing rock mechanics (RSRM) was put forward, and it could serve in the forecasting of time-space location of potential rock failure events by IRR monitoring (Wu et al. 2000). Based on a series of experiments of IRR features for multiple rocks under different loading conditions, it was revealed that the detected temperature would reflect the IRR energy variation, and that the abnormal IRR precursors could provide forewarning information for rock failure (Wu et al. 2001; Cui et al. 1993; Geng et al. 1992). Wu et al. (2006a, b) found that thermogram abnormality and temperature curve abnormality were detected as precursors of rock fracture. Three precursor messages-short dropping, fast rising and dropping-to-rising were observed using the temporal evolution features of average infrared radiation temperature curves (Wu et al. 2006a, b).

It is difficult to carry out the experiment of rockmass load/unload condition on site due to the constraints of various actual conditions. Meanwhile, laboratory test methods can respond to engineering applications in a certain degree. Therefore, it is of great significance to make the research on rock failure predicting in the laboratory.

In this chapter, based on previous research results, we performed the tests in laboratory and research the precursory information before rockburst in field. At present, the technology of rock failure predicting is applied in a single, hysteresis and poor effect, which can not timely, comprehensively and effectively predict the hazards. Therefore, it is very important to establish a multi-means monitoring and cooperative predicting for rockburst. In this chapter, we studied on the predicting key point of rockburst used the stress-strain monitoring, AE monitoring, infrared monitoring, microseismic monitoring, et al. 


\subsection{Predicting Points of Infrared Precursor for Coal Failure}

\subsubsection{Laboratory Test of Coal Failure}

In this chapter, as shown in Fig. 7.1, coal specimens were cylindrical cores with a diameter of $50 \mathrm{~mm}$ and a length of $100 \mathrm{~mm}$. Two end planes of every specimen were parallel within an accuracy of $\pm 0.05 \mathrm{~mm}$, and both planes were perpendicular to the longitudinal axis with an accuracy of $\pm 0.25^{\circ}$, and actual size and mechanic parameters (Table 7.1).

$\mathrm{AE}$ sensors were glued approximately $20 \mathrm{~mm}$ from the two end planes to reduce the interference for $\mathrm{AE}$ data collection. The sampling frequency of sensor and specimen was $1 \mathrm{MHz}$, and $\mathrm{AE}$ signal acquisition threshold was set to $40 \mathrm{~dB}$. Based on coal specimen's ultimate compression strength (UCS), experiments were divided into three-section uniaxial cyclic load/unload process. Coal specimens were loaded at $200 \mathrm{~N} / \mathrm{s}$. In the first phase, coal specimens were loaded from 8 to $16 \mathrm{MPa}$ before being unloaded back to $8 \mathrm{MPa}$. In the second phase, coal specimens were loaded from 16 to $24 \mathrm{MPa}$ before being unloaded back to $16 \mathrm{MPa}$. In the third phase, coal

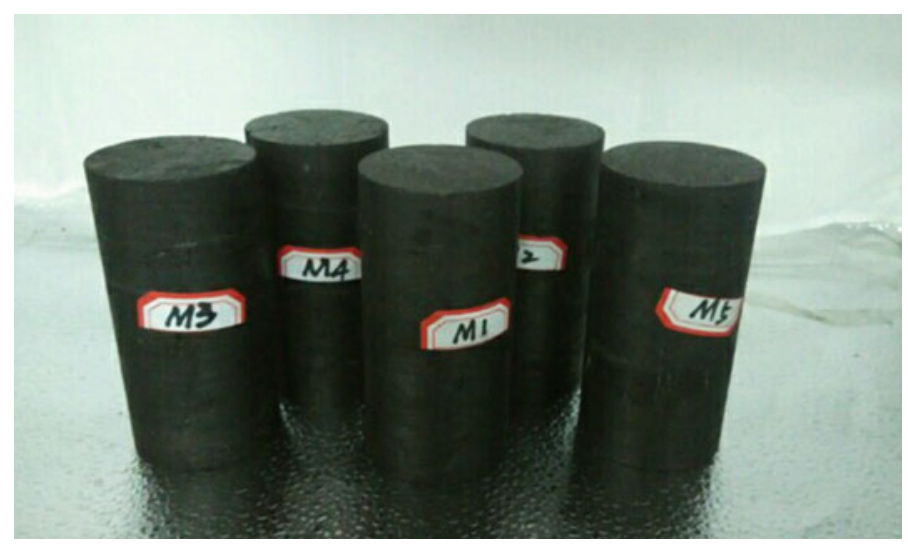

Fig. 7.1 Photos of coal specimens

Table 7.1 Summary of coal specimens

\begin{tabular}{l|l|l|l|l|l|l}
\hline $\begin{array}{l}\text { Specimen } \\
\text { ID }\end{array}$ & $\begin{array}{l}\text { Diameter } \\
(\mathrm{mm})\end{array}$ & $\begin{array}{l}\text { Height } \\
(\mathrm{mm})\end{array}$ & $\begin{array}{l}\text { Weight } \\
(\mathrm{g})\end{array}$ & $\begin{array}{l}\text { Density }(\mathrm{g} / \\
\left.\mathrm{cm}^{3}\right)\end{array}$ & $\begin{array}{l}\text { Elastic } \\
\text { modulus (Gpa) }\end{array}$ & $\begin{array}{l}\text { UCS } \\
(\mathrm{MPa})\end{array}$ \\
\hline M1 & 49.61 & 99.51 & 245.80 & 1.278 & 2.58 & 39.51 \\
\hline M2 & 49.66 & 99.25 & 245.34 & 1.276 & 2.36 & 27.84 \\
\hline M3 & 49.63 & 99.86 & 241.47 & 1.250 & 2.32 & 26.83 \\
\hline M4 & 49.95 & 99.18 & 272.68 & 1.403 & 2.93 & 28.60 \\
\hline M5 & 49.73 & 99.79 & 247.59 & 1.277 & 2.19 & 27.73 \\
\hline
\end{tabular}




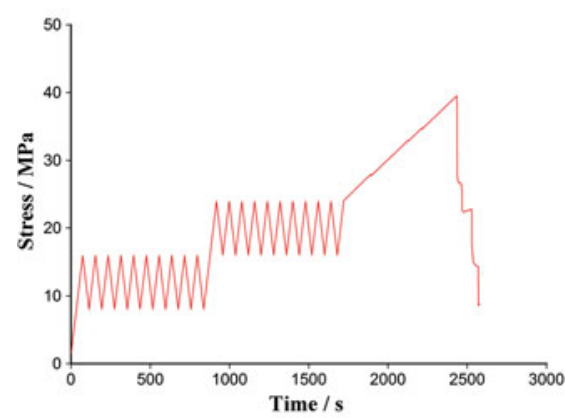

(a) Loading path.

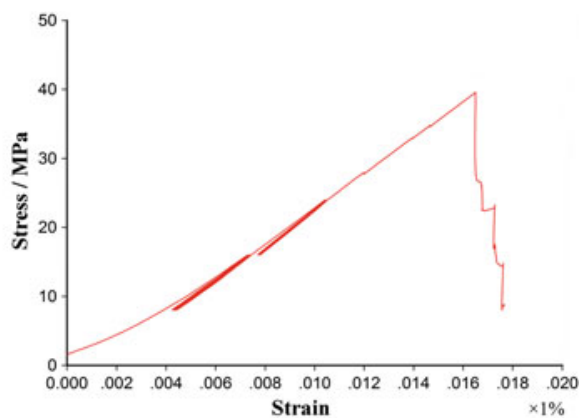

(b) Loading-unloading curve of the coal specimens.

Fig. 7.2 Testing curve and path for coal specimens

specimens were continuously loaded from $16 \mathrm{MPa}$ until failure. Cyclic loading path of coal specimens was shown in Fig. 7.2. AE monitoring was carried out real time dynamically during loading. Meanwhile, infrared radiation (IRR) experiments were be monitored.

Regard to the thermographic camera, the graphic recording rate was set to 4 frames per second. InfRec R300 directly faced rock sample surface approximately $1 \mathrm{~m}$ from samples. IRR on rock surface was debugged before rock samples were loaded. The ambient temperature and humidity in the laboratory were tested before the experiment. The ambient temperature was $22.10{ }^{\circ} \mathrm{C}$, and the humidity was $29 \%$. The emissivity of tested coal sample was 0.92. In the experiment, TAW-2000 and InfRec R300 were operated simultaneously during the whole deformation and fracture processes on the coal samples.

\subsubsection{Theoretical Bases of IRR Detection}

Temperature is a comparative objective parameter of hot and cold. It reflects the thermal state of object and can be measured in a contact or noncontact method. The noncontact mode is based on the measurement of IRR emitted from the object surface. Thermal radiation is the emission of electromagnetic waves from all matter with a temperature greater than absolute zero. It is among three fundamental modes of heat transfer and represents a conversion of thermal energy into electromagnetic energy. Examples of thermal radiation include visible light emission and infrared light radiation. Based on the electromagnetic spectrum, IRR is invisible infrared light emission with wavelength higher than that of visible light, and lower than that of microwaves ranging from approximately $760 \mathrm{~nm}$ to $1000 \mu \mathrm{m}$. Moreover, physical parameters of infrared radiation may be occured the energy jump of molecule oscillation or rotation. In general, objects emit IRR across a spectrum of wavelengths. 
In thermal radiation theory, Planck's law is the basic regulation for black body radiation. Planck's law theoretically illuminates the relationship among spectral radiance, wavelength and thermodynamic temperature of black body. Planck's law was given as (Planck 1959):

$$
\mathrm{B}_{\lambda}(\lambda, \mathrm{T})=\frac{2 h c^{2}}{\lambda^{5}} \cdot \frac{1}{\mathrm{e}^{c h / \lambda k T-1}}
$$

where $\mathrm{B}_{\lambda}$ is the spectral radiance, $\mathrm{W} \mathrm{m}^{-2} \mu \mathrm{m}^{-1} ; c$ is the speed of light, $\mathrm{m} \mathrm{s}^{-1} ; h$ is Planck's constant, $\mathrm{J} s ; \lambda$ is the wavelength, $\mu \mathrm{m} ; \mathrm{T}$ is the absolute temperature of object, $\mathrm{K}$; And $k$ is the Stefan-Boltzmann constant, $\mathrm{J} \mathrm{m}^{-2} \mathrm{~K}^{-4}$.

Planck's law gives the spectral blackbody emissive power distribution in thermal equilibrium at different temperatures. The spectral radiance of a body indicates the amount of energy it gives off as radiation of different wavelengths. The Planck radiation has a maximum intensity at a specific wavelength that depends on the temperature. In addition, it is also revealed that the higher the temperature of a body, the more radiation it emits at every wavelength. Therefore, the radiant properties of a black body are only dependent on the absolute temperature and have nothing to do with the material composition.

In this chapter, the thermographic camera was applied in the passive mode without the use of any extra heat resources. Infrared thermography (IRT) could visualized the temperature changes over the viewed rock surface. When coal samples were loaded, the thermographic camera was used to observe and capture IRR variation during the whole loading process. In the IRR detection test, temperature data and thermograms of coal surface would be obtained. IRR emitted from coal surface was detected by the focal plane array (FPA) detector in the thermographic camera. The emitted infrared radiation was transformed into temperature by thermographic camera, so temperature reflected the radiant energy emitted from the object. By calibration, the relation between surface temperature and radiation could be established. The relationship between radiant energy and thermodynamic temperature of loaded coal samples was interpreted by the Stefan-Boltzmann law (Boltzmann 1884):

$$
\mathrm{M}=\varepsilon \sigma T^{4}
$$

where $\mathrm{M}$ is the radiant exitance, $\mathrm{W} \mathrm{m}^{-2} ; \varepsilon$ is the emissivity of object, $0<\varepsilon<1 ; \sigma$ is the Stefan-Boltzmann constant, $\mathrm{J} \mathrm{m}^{-2} \mathrm{~K}^{-4}$; and $\mathrm{T}$ is the absolute temperature of object, $\mathrm{K}$.

Stefan-Boltzmann law described the radiation emitted from an object in its absolute temperature. Meanwhile, Stefan-Boltzmann law stated the total energy radiated per unit surface area of an object across all wavelengths per unit time. Given that the tested samples were small-scale sized and coal surface was smooth, we assumed that the emissivity values were constant for wavelengths emitted from the surface. In other words, coal sample was approximatively regarded as a grey body. According to Stefan-Boltzmann law, the radiation intensity of loaded 
specimen was biquadratic to its absolute temperature. Temperature was an important indicator of IRR intensity and could reflect the radiant energy variation quantitatively. Therefore, temperature on coal surface was used to illustrate an index reflecting the thermal state and the complicated physico-mechanic process inside the loaded coal samples (Wu et al. 2006a, b).

Regarding the thermogram on coal surface, it is composed of a matrix of pixels whose temperature varies with stress during the loading process. Moreover, the temperature of each pixel at different locations may differ significantly. Therefore, the mean temperature of coal surface was introduced to describe the overall IRR variation of loaded coal samples during the deformation process. The mean temperature for each thermogram of the same coal sample could be calculated and analysed by the thermographic camera. The mean temperature was a general reflection of surface IRR energy of loaded rock, and could be selected as the integral index to study the temporal evolution of IRR (Wu et al. 2006a, b). In the experiment, the thermograms were visually shown on the display screen of thermographic camera, and the temperature data were easily obtained and stored with the use of IRT technique.

\subsubsection{IRT Characteristics of Coal Samples}

Temperature changed on the overall surface of coal samples were recorded during the process of uniaxial compression. To facilitate description of experimental results of tested coal samples, author chose representative sample M4 as an example. Figure 7.1 showed the relationship between stress-strain curve of limestone sample and mean temperature on the coal surface during the entire loading process. The deformation and fracturing processes of loaded coal samples had four stages, including the original crack compaction stage, the elastic deformation stage, the plastic deformation stage and the post-peak failure stage. As shown in Fig. 7.3, IRR was observed and detected during the entire loading process. The mean temperature on the sample surface varied with the progress of loading and had stage-changed characteristics:

(1) Initial loading and frist cycle phase: This stage was approximately $20 \%$ of the entire loading process. The concaved upwards curve during this stage indicated the closure of original microstructure under the uniaxial compression. As shown in Fig. 7.3, the average temperature rises at the beginning of loading. Subsequently, it changed from rise to down, and then rase again. It fluctuated significantly at early stage, with the maximum temperature fluctuating by $1.45{ }^{\circ} \mathrm{C}$. The reason might be due to the internal microfracture closure of coal sample.

(2) The second cycle phase and the phase before failure: This stage was approximately $40 \%$ of the entire loading process. At the end of the second cycle stage, 


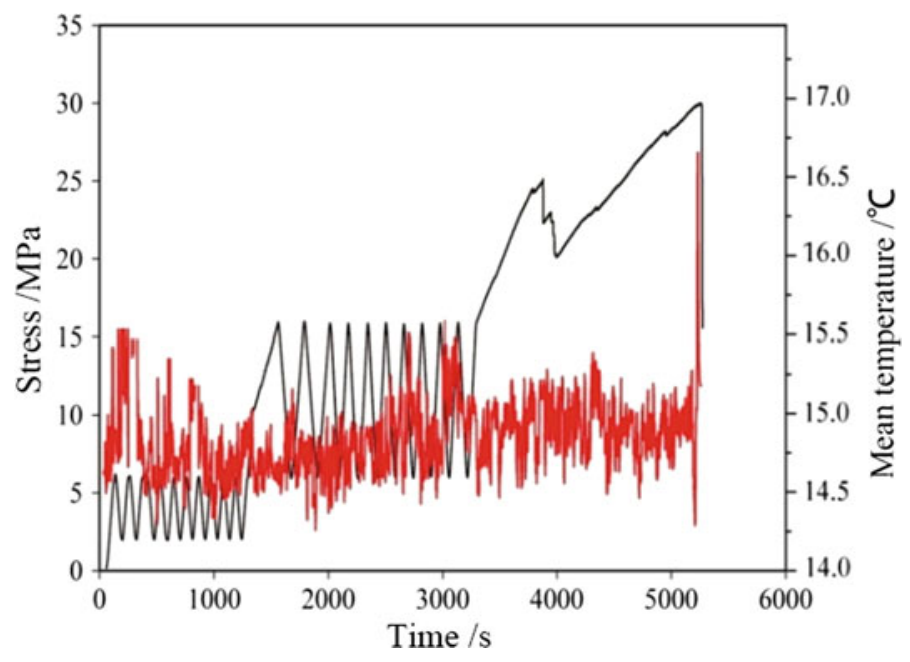

Fig. 7.3 Relationship between the stress-strain curve and the mean temperature

the average maximum temperature was appeared. With the loading into the circulation in the third phase (the phase before failure), average temperature started to down, and then into the relatively stable fluctuation period until to coal failure. In the period of fluctuation in about $4300 \mathrm{~s}$, there was a local maximum values of about $15.3{ }^{\circ} \mathrm{C}$. This was consistent with the dilatancy of coal sample during loading. With the increase of load, micro-cracks initiated, propagated, and merged progressively, the volume of coal samples began to swell, and the average infrared radiation temperature fluctuation regularity.

(3) The failure stage: In this stage, the stress dropped sharply to zero, and sample rupture occurred. Accordingly, the mean temperature decreased quickly after the peak stress.

As shown in Fig. 7.4, thermal radiation was detected and obtained in the entire loading process. The mean temperature of sample surface changed with time and period feature. Infrared radiation temperature percentage change had good regularity during the whole loading process of coal sample. In the compaction stage and elastic stage, the range of infrared radiation temperature distribution was relatively wide. In the plastic stage and failure time, the average temperature was high, especially the moment of destruction, average infrared radiation temperature of the maximum percentage was up to $16.3{ }^{\circ} \mathrm{C}$, as shown in $\mathrm{F}$ point in Fig. 7.4 , the average temperature increased approximately $2{ }^{\circ} \mathrm{C}$.

Analyzing the temperature variation features in different regions on rock sample surface, three different regions, region $\mathrm{A}$, region $\mathrm{B}$ and region $\mathrm{C}$, were delineated on the thermogram, as shown in Fig. 7.5. It was noted that region $\mathrm{B}$ and region $\mathrm{C}$ in 


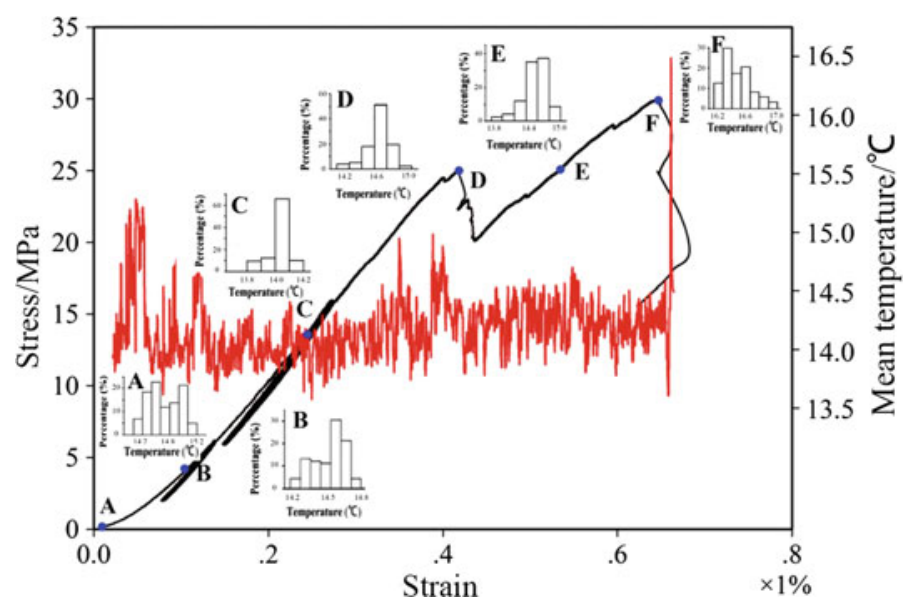

Fig. 7.4 Relationship between the stress-strain curve and the mean temperature

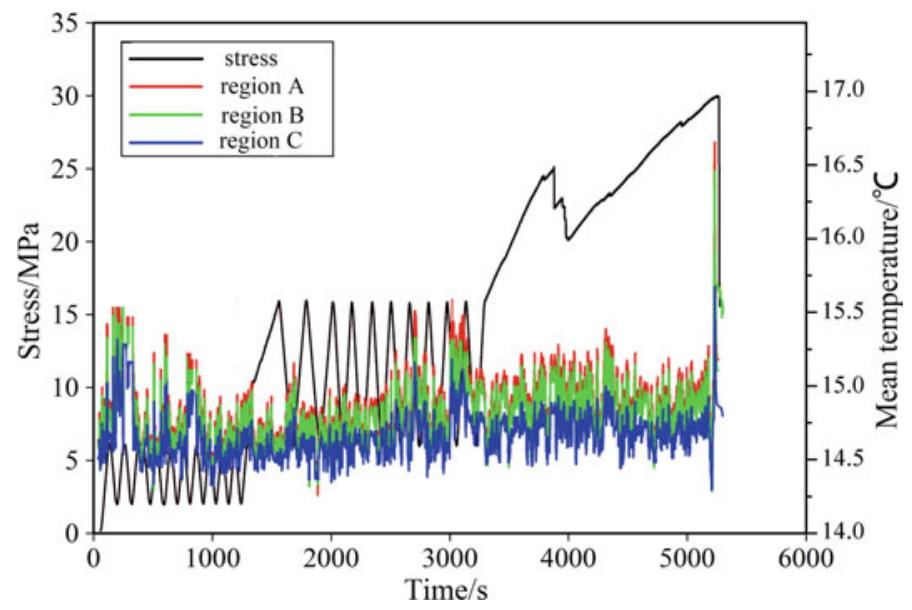

Fig. 7.5 Mean temperature variations in the three different regions

Fig. 7.5 were the fracturing regions at failure. Figure 7.6 showed the evolution of mean temperature in different regions in the entire loading process.

Analyzing the temperature variation features in different regions on rock sample surface, three different regions, region $\mathrm{A}$, region $\mathrm{B}$ and region $\mathrm{C}$, were delineated on the thermogram. As shown in Figs. 7.5 and 7.6, the evolution of mean temperature was showed in different regions in the entire loading process.

As shown in Fig. 7.6, variation trend of the mean temperature in three different regions was consistent on the whole sample. The mean temperature of region B was 
Fig. 7.6 Three different delineated regions in the thermogram

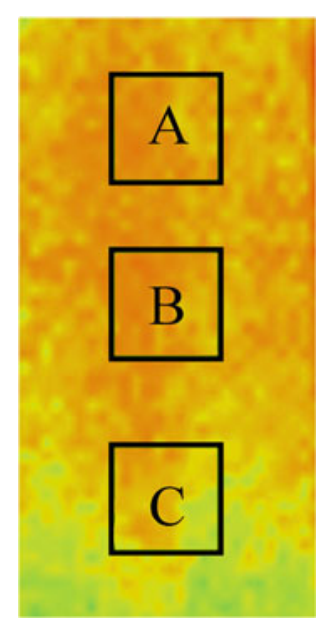

slightly lower than that in region $\mathrm{A}$, and much higher than that in region $\mathrm{C}$ during rock deformation period. It was pointed out that mean temperature of overall rock surface was between the mean temperature in region $\mathrm{A}$ and the mean temperature in region $\mathrm{B}$, indicating that region $\mathrm{C}$ was the low-temperature IRR region, whereas region $\mathrm{A}$ and region $\mathrm{B}$ were the high-temperature regions.

An abnormal precursory phenomenon of "rising-dropping-rising" in the average temperature appeared at the end of loading process. Especially, at the time about $4300 \mathrm{~s}$, average temperature change of regional $\mathrm{C}$ was not large while the average temperature increased significantly in the region $\mathrm{A}$ and $\mathrm{B}$. In addition, when the load was at peak stress, the average temperature of region A was about $16.6{ }^{\circ} \mathrm{C}$, region $\mathrm{B}$ was about $16.47{ }^{\circ} \mathrm{C}$, and region $\mathrm{C}$ was about $15.65^{\circ} \mathrm{C}$. That is to say, the average temperature of region $\mathrm{A}$ and region $\mathrm{B}$ was close, while region $\mathrm{C}$ was much lower than that of A and B, which indicated that the main inside cracks of sample was located in the upper part of sample, where a large number of infrared heat radiation were released. This phenomenon could help locate the damage of coal sample.

Given that the initial mean temperatures in the three regions were different, the mean temperature variation ranges at the same time were not shown. Therefore, investigating the mean temperature variation ranges in different regions during the loading process, we defined the difference between the mean temperature at a certain loading time and the initial mean temperature at the initiation of loading as the mean temperature increment. As shown in Fig. 7.7, the mean temperature increment of three areas of coal sample was shown during the whole loading process, the difference increment of the average temperature between the three regions during the initial loading phase was relatively low and the curve 


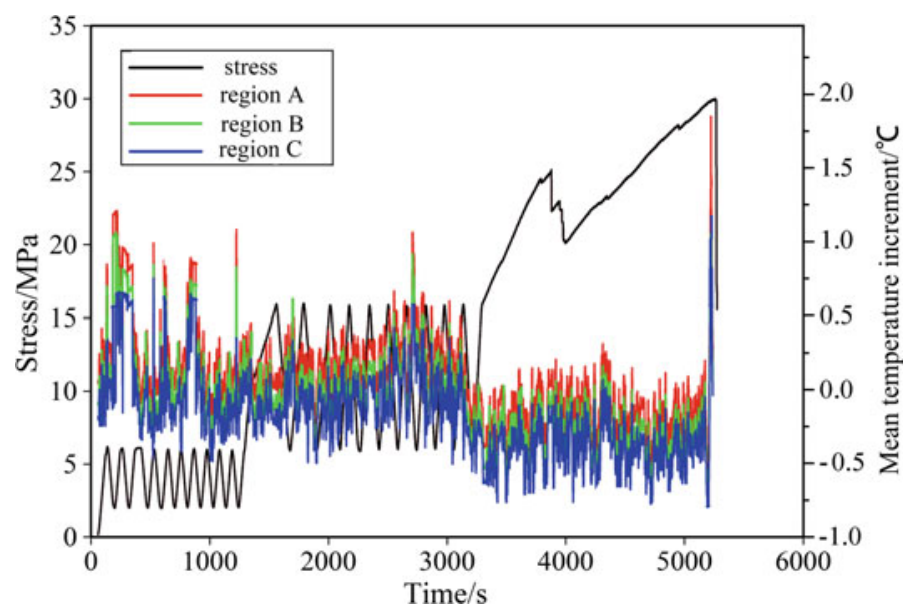

Fig. 7.7 Mean temperature increment variations in the three different regions

coincidence was relatively high. However, the average temperature increment of three different regions, with the persistence of loading, especially after $1300 \mathrm{~s}$, began to show different changes, and the coincidence degree of the average temperature increment curve in three different regions decreased. As shown in Fig. 7.7, the average temperature increment of region A was slightly higher than region B, which was higher than region $\mathrm{C}$. All three different regions showed an anomalous precursory phenomenon of "rising-dropping-rising" before the peak pressure in the average temperature increment. As for the average temperature increment, the fluctuations of temperature increment in three regional were comparatively evident at the beginning of $1000 \mathrm{~s}$. From 1500 to $2800 \mathrm{~s}$, the average temperature increment in three regions increased steadily and the temperature increment increased by nearly $1{ }^{\circ} \mathrm{C}$. This $1{ }^{\circ} \mathrm{C}$ was obtained at about $2800 \mathrm{~s}$ in both region $\mathrm{A}$ and $\mathrm{B}$, while the average temperature increment of $\mathrm{C}$ was about $0.5^{\circ} \mathrm{C}$. After then, the average temperature increment began to decrease, the average temperature increment of region $\mathrm{A}$ and $\mathrm{B}$ drops to $-0.5{ }^{\circ} \mathrm{C}$ and began to change smoothly, where the number of $\mathrm{C}$ was $-0.75{ }^{\circ} \mathrm{C}$. When stress of coal sample reached the peak value, the average temperature increment of region $\mathrm{A}, \mathrm{B}$ and $\mathrm{C}$ were $1.8,1.5$ and $1.2{ }^{\circ} \mathrm{C}$, respectively. It was proved that the average temperature increment of region $\mathrm{A}$ and $\mathrm{B}$ was significantly higher than region C. At the peak pressure, coal sample had a major rupture in region $\mathrm{A}$, which showed obvious spots and streaks in the infrared thermal image, which indicated that monitoring captured higher radiation temperatures and extremely dense radiation appearances. After the loading peak, the average temperature increment of three regions decreased instantaneously when pressure value suddenly decreased, and coal sample was finally failure. 


\subsubsection{IRT Prediction for Rock Failure}

The mean temperature on the coal surface, as a quantitative index, was used to characterize the evolution of temperature field during the entire loading process. As stated previously, the mean temperature abnormality of "rising-dropping-rising" in the later loading period was considered as the temperature curve precursor for rock failure. Accordingly, the abnormal precursors of obvious high temperature bright spots or bright bands in the infrared thermal image showed that a large amount of infrared radiation energy was released, and coal sample would be failure. Combined with the anomalies of average temperature increment curve and the anomaly of infrared thermal image, the infrared anomaly precursors could be taken as the infrared precursors of coal samples failure. Therefore, the mean temperature increment interval of "dropping-rising" could be used as a predicting point for coal failure (as shown in Fig. 7.8).

The abnormal precursors on thermograms and on the mean temperature curve occurred synchronously before coal failure. Thus, the mean temperature and thermograms should be analysed comparatively, and it would be more accurate and effective for identifying the infrared precursor of rock failure or mine hazards. On the one hand, the mean temperature was used as a quantitative index to identify the abnormal precursor points, including the predicting point and the key predicting point, which presented the potential collapse time. On the other hand, the spatiotemporal evolution of thermograms could reflect the temperature distribution with time, and the spatial location of abnormal precursor on the thermogram might help predict the anticipated collapse area. Based on the integrated investigation on the mean temperature precursor and the thermogram precursor, it was easier to

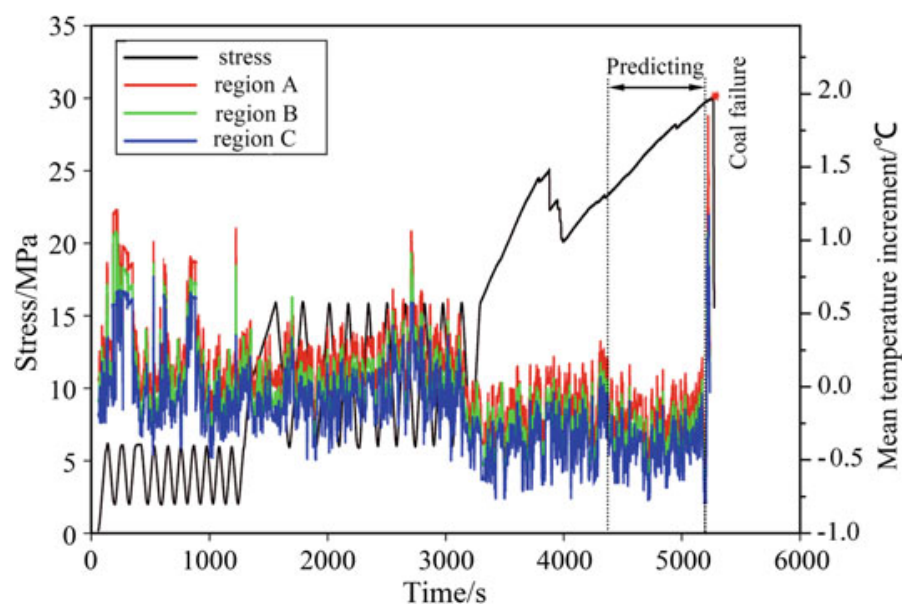

Fig. 7.8 Prediction of coal failure by mean infrared radiation temperature increment 
predict potential hazards and obtain its potential occurrence time and location. Therefore, effective measures could be made timely to prevent losses of personnel and equipment.

\subsection{Experimental Investigation on Predicting Rock Failure Using Load/Unload Energy Response Ratio Theory}

\subsubsection{LURR Characteristics of Coal Samples}

Based on the experiment of Sect. 7.2, AE energy was collected to calculate the total amount of AE energy, the summation for AE energy release square root and LURR $\left(Y_{1}\right.$ and $\left.Y_{2}\right)$. The calculated results of coal specimen M1 in the second stage were schematically shown in Table 7.2. Based on LURR theory, the loading response

Table 7.2 AE energy results collected and analysed from the loading process of coal sample M1

\begin{tabular}{|c|c|c|c|c|c|c|c|}
\hline No. & $\begin{array}{l}\text { Loading } \\
\text { way }\end{array}$ & $\begin{array}{l}\text { Start } \\
\text { time }\end{array}$ & $\begin{array}{l}\text { End } \\
\text { time }\end{array}$ & $\begin{array}{l}\text { AE energy } \\
\text { summation/ } \\
\mathrm{J}\end{array}$ & $\begin{array}{l}\text { LURR } \\
\left(Y_{1}\right)\end{array}$ & $\begin{array}{l}\text { Summation for AE } \\
\text { energy release square } \\
\text { root// } \mathbf{J}^{1 / 2}\end{array}$ & $\begin{array}{l}\text { Benioff } \\
\text { strain } \\
\left(Y_{2}\right)\end{array}$ \\
\hline \multirow[t]{2}{*}{1} & Loading & 877 & 917 & 109,861 & \multirow[t]{2}{*}{5.13034} & $16,794.65$ & \multirow[t]{2}{*}{6.73718} \\
\hline & Unloading & 918 & 957 & 21,414 & & 2492.83 & \\
\hline \multirow[t]{2}{*}{2} & Loading & 958 & 997 & 23,727 & \multirow[t]{2}{*}{3.44569} & 2903.99 & \multirow[t]{2}{*}{2.72167} \\
\hline & Unloading & 998 & 1037 & 6886 & & 1066.99 & \\
\hline \multirow[t]{2}{*}{3} & Loading & 1038 & 1077 & 9810 & \multirow[t]{2}{*}{2.56874} & 1386.53 & \multirow[t]{2}{*}{1.91936} \\
\hline & Unloading & 1078 & 1118 & 3819 & & 722.39 & \\
\hline \multirow[t]{2}{*}{4} & Loading & 1119 & 1158 & 5265 & \multirow[t]{2}{*}{1.11476} & 879.96 & \multirow[t]{2}{*}{1.23550} \\
\hline & Unloading & 1159 & 1198 & 4723 & & 712.23 & \\
\hline \multirow[t]{2}{*}{5} & Loading & 1199 & 1238 & 5070 & \multirow[t]{2}{*}{1.61722} & 672.63 & \multirow[t]{2}{*}{1.42903} \\
\hline & Unloading & 1239 & 1278 & 3135 & & 470.69 & \\
\hline \multirow[t]{2}{*}{6} & Loading & 1279 & 1319 & 2195 & \multirow[t]{2}{*}{0.82210} & 384.52 & \multirow[t]{2}{*}{1.18179} \\
\hline & Unloading & 1320 & 1359 & 2670 & & 325.37 & \\
\hline \multirow[t]{2}{*}{7} & Loading & 1360 & 1399 & 2695 & \multirow[t]{2}{*}{1.07200} & 414.92 & \multirow[t]{2}{*}{1.13094} \\
\hline & Unloading & 1400 & 1439 & 2514 & & 366.88 & \\
\hline \multirow[t]{2}{*}{8} & Loading & 1440 & 1479 & 3422 & \multirow[t]{2}{*}{1.33411} & 408.43 & \multirow[t]{2}{*}{1.05149} \\
\hline & Unloading & 1480 & 1520 & 2565 & & 388.43 & \\
\hline \multirow[t]{2}{*}{9} & Loading & 1521 & 1560 & 1898 & \multirow[t]{2}{*}{1.23007} & 363.37 & \multirow[t]{2}{*}{1.01953} \\
\hline & Unloading & 1561 & 1600 & 1543 & & 356.41 & \\
\hline \multirow[t]{2}{*}{10} & Loading & 1601 & 1640 & 1689 & \multirow[t]{2}{*}{0.99004} & 221.16 & \multirow[t]{2}{*}{0.97548} \\
\hline & Unloading & 1641 & 1680 & 1706 & & 226.72 & \\
\hline
\end{tabular}

Note Only the testing results from coal specimen M1 were included in Table 7.2, in consideration of mass data from all the five coal specimens 
rate of coal specimens was equal to the unloading rate, or $X_{+}=X_{-}$in the first stage. In addition, research on predicting rockburst was principally focused on the plastic deformation stage. Little attention was paid on AE energy in this chapter.

The variation characteristics associated with coal specimen failure could be obtained based on LURR theory and AE energy. In Table 7.2, the total AE energy was observed for an abnormal phenomenon during No. 1 step. Additionally, the summation for AE energy release square root was also observed for abnormal phenomenon during No. 1 step. These phenomenons played a meaningful role in predicting rockbursts.

In the laboratory experiment, AE energy expressed the variations in the different stress states. Figure 7.9 shows AE energy variation process of all coal specimens. The mechanical behaviour of coal specimens could be determined by the original cracks compaction and elastic deformation. During the loading process, the original cracks in coal specimen were gradually closed. Due to the heterogeneity of coal specimens, the internal partial region of coal specimens quickly produced stress concentration. Thus, AE energy was increased obviously. Strong AE energy signals were mainly a result of coal grain sliding friction and internal micro-crack closure. However, during the first stage of load/unload process, AE signals were mainly caused by coal grain sliding friction, which resulted in a small amount of AE energy release.

In the second stage shown in Table 7.2, the stable-unstable development of micro-cracks and elasto-plasticity deformation were analytical gained.
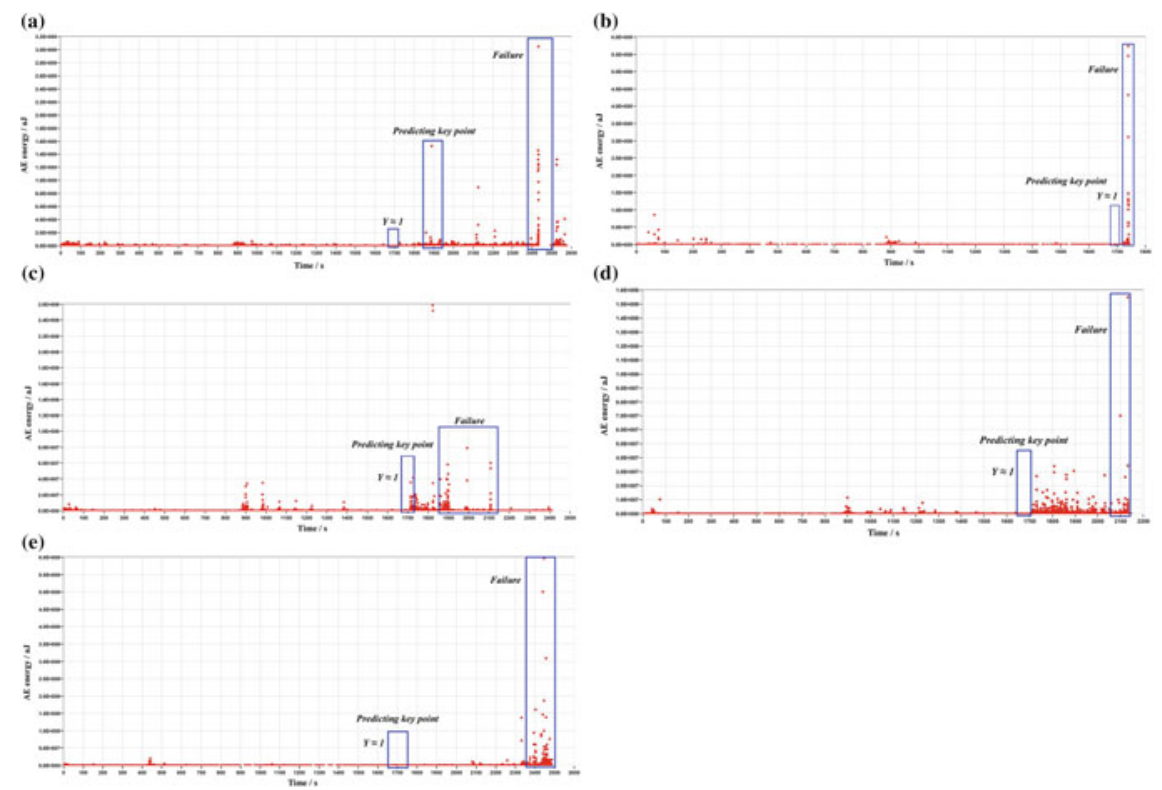

Fig. 7.9 AE energy release of coal specimens 
Developmental variations in the micro-cracks and failures of coal specimens were analysed. These fractures could be recovered due to stress concentration, strain energy release and AE energy release. During the load/unload process, the extension of internal natural micro-cracks and formation of new micro-cracks lead to a weakening in the mechanical properties (such as compressive strength and void ratio) of coal specimens.

As shown in Fig. 7.9, AE energy was released during the first stage less than that the second and third stage. During the second stage, the release of AE energy was apparent, indicating that new cracks were generated in coal specimens and propagated rapidly. When coal specimens were loaded into the third section, the intensive AE energy release of coal specimens was more obvious. A great deal of AE energy release was mainly concentrated before coal failure. Then, AE energy release of coal specimens decreased rapidly. This phenomenon could be used as the precursor information of coal failure. Similar conclusions related to predicting key points were obtained using AE/MS monitoring, AE energy and LURR theory. However, as shown in Fig. 7.9a, AE energy of coal specimen M1 was suddenly concentrated released in a period of time before coal specimens' failure. This phenomenon could be due to the difference of brittleness and heterogeneity of five coal specimens.

$\mathrm{AE}$ energy data were obtained to analysis in the experiments. According to LURR equation, AE energy data were processed and analysed using two methods. The total AE energy release in the second stage was proposed as a response rate $(X)$ in the first method. In the other way, the response rate $(X)$ was denoted by the summation for AE energy release square root in the second stage. This study focused on precursor information of rockburst during the plastic deformation stage.

As a result of suddenly AE energy concentrated release before coal failure, the mechanism of rockburst could be revealed using energy analysis. Many results were obtained by scholars; For example, the total energy release was considerably higher under dry state than saturated state, which is the same as the shallow bedding orientation (Wasantha et al. 2014). Energy propagation was determined by elastic strain energy (Rudnicki and Sternlof 2005). Therefore, the release of AE energy was used as a parameter to examine the prediction of rockburst in this study. As shown in Table 7.2 and Fig. 7.9, AE energy release in the first step was extremely larger than that in the other steps. Then, AE energy release began to reduce continuously. Based on the data collected in the test, many parameters change characteristics were obtained, such as the total AE energy, LURR $\left(Y_{1}\right)$, the summation for AE energy release square root and Benioff strain $\left(Y_{2}\right)$. From the first step to the third step of sample M1 in Table 7.2, AE energy in the loading step was obviously higher than that in the unloading step, and LURR value $\left(Y_{1}\right)$ was larger than 1 . During the sixth step, AE energy in the loading step was clearly less than in the unloading step, and LURR value $\left(Y_{1}\right)$ was less than 1 . During the seventh to tenth steps, AE energy in the loading step was closest to that in the unloading step, and LURR value $\left(Y_{1}\right)$ was close to 1 . However, based on the summation of AE energy release square root from the first step to fifth step, the value of summation for $\mathrm{AE}$ energy release square root during loading was greater than that during unloading, 


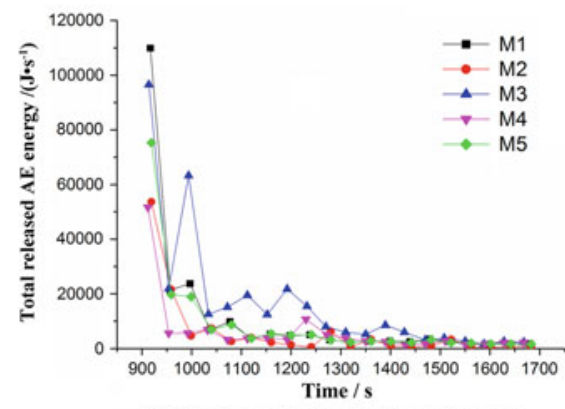

(a) Total variation in the released AE energy.

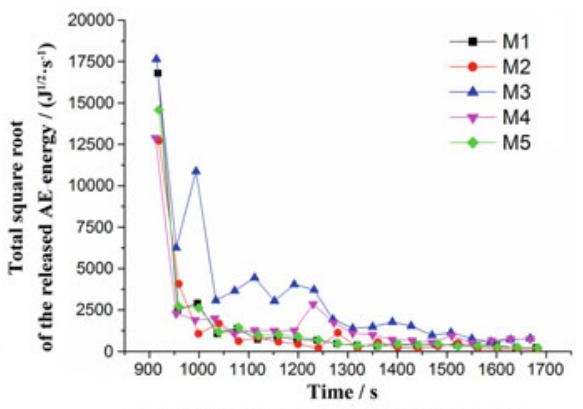

(b) Total Square root of the released AE energy.

Fig. 7.10 Variations of AE energy released of coal specimens under uniaxial load/unload condition

and Benioff strain $\left(Y_{2}\right)$ was larger than 1. During the 6-th step to 10-th step, the value of summation for AE energy release square root in the loading step was closest to that in the unloading step, and Benioff strain $\left(Y_{2}\right)$ was close to 1 . This phenomenon illustrated that more AE energy was released during loading than unloading. The micro-cracks in the coal samples were compacted in the first three loading steps.

As shown in Fig. 7.10, the variation characteristics of AE energy were highly consistent with the summation of AE energy release square root for specimens. These two parameters had similar change processes, as the initial released energy was larger than that after the sharp decrease. Meanwhile, the variation tendency of these two parameters became to a steady change after the sharp decrease. The internal micro-crack growth in the sample was mainly consistent with the energy release. The released AE energy variation could infer that the concentrated release of AE energy occurred at the beginning of the second stage. Then, AE energy accumulated before coal failure. Consequently, AE energy accumulation in plastic deformation stage could be used as precursor for rockburst.

\subsubsection{LURR Prediction of Coal Failure}

In this chapter, LURR $\left(Y_{1}\right)$ and Benioff strain $\left(Y_{2}\right)$ were used to analyse coal failure based on AE energy data and the relationship in Eq. (3.5). Figure 7.11 shows the variation characteristics of LURR $\left(Y_{1}\right)$ and Benioff strain $\left(Y_{2}\right)$. The trends of $Y_{1}$ and $Y_{2}$ values were highly similar and could be used to predict coal failure. $Y_{1}$ and $Y_{2}$ values were both larger at the beginning of the second stage. Then, they fluctuated around 1. Finally, both $Y_{1}$ and $Y_{2}$ values were close to 1 at the end of the second stage. The initial deformation and degree of damage of coal specimens could be determined based on the trends in $Y_{1}$ and $Y_{2}$ values. 


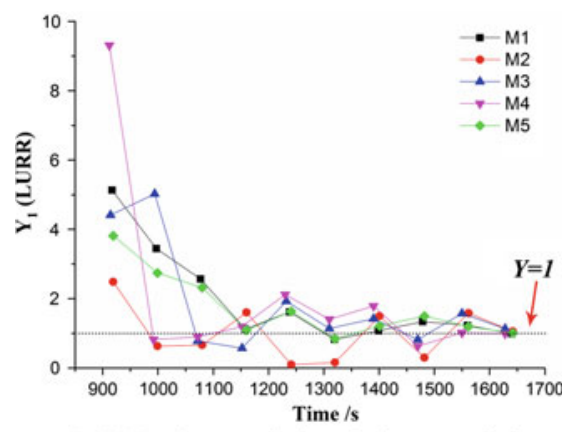

(a) $Y$, value variational characteristics.

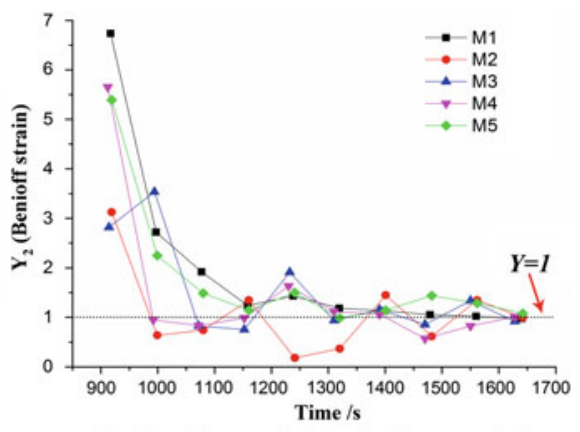

(b) $Y_{2}$ value variational characteristics.

Fig. 7.11 Variation characteristics of LURR $(Y 1)$ and Benioff strain $(Y 2)$ of coal specimens

As shown in Figs. 7.10 and 7.11, the fluctuation of $Y_{1}$ and $Y_{2}$ values was consistent with the AE energy accumulation on the time series. Therefore, LURR variation trend (the $Y_{1}$ and $Y_{2}$ values were both close to 1) could be viewed as precursor information for rockburst. The time points, where $Y_{1}$ and $Y_{2}$ values, were both close to 1 , they could be used as the predicting key point of coal failure. This point could be measured before coal failure. What is more, after this time point, coal specimens destroy completely in a short time. Thus, LURR theory, which combined with AE energy under uniaxial cyclic load/unload conditions, could be used to predict rockburst. Inevitably, this method still has shortcomings. Affected by the constitutive properties and loading speed of coal specimens, the time between the predicting key point and the time point of coal failure was very difficult to determine, which still needed more researches in the future.

\subsection{Experimental Investigation on Predicting Points Using Tangent Damage Factor for Rock Failure}

\subsubsection{Laboratory Test of Rock Failure}

In the experiment, the limestone specimens were taken from coal roof of Xie Zhuang coal mine in Shandong province. The mining depth is $1212 \mathrm{~m}$. With the depth of mining operation, mine disasters have occurred more easily than ever before. The limestone specimens were processed in the form of wet processing method in the laboratory. All samples were prepared in accordance with International Society for Rock Mechanics (ISRM) suggested shape and size and were processed into cylinders measuring approximately $50 \mathrm{~mm}$ in diameter and $100 \mathrm{~mm}$ in height, as shown in Table 7.3. Finally, six samples were obtained. Meanwhile, both the specimens' ends were polished when processing them and the unevenness of surface was controlled less than $0.05 \mathrm{~mm}$. Both the specimens' ends 
Table 7.3 The physical-mechanical parameters of 6 limestone samples

\begin{tabular}{l|l|l|l|l}
\hline Specimen ID & Height $(\mathrm{mm})$ & Diameter $(\mathrm{mm})$ & Density $\left(\mathrm{g} \mathrm{cm}^{-3}\right)$ & UCS $(\mathrm{MPa})$ \\
\hline $\mathrm{X} 1$ & 98.54 & 49.52 & 2.61 & 131 \\
\hline $\mathrm{X} 2$ & 102.12 & 51.20 & 2.85 & 132 \\
\hline $\mathrm{X} 3$ & 99.42 & 48.70 & 2.68 & 108 \\
\hline X4 & 97.84 & 48.30 & 2.64 & 103 \\
\hline X5 & 101.2 & 50.50 & 2.71 & 131 \\
\hline X6 & 99.28 & 48.64 & 2.66 & 130 \\
\hline
\end{tabular}

were perpendicular to the axis and the tolerance of angle was less than $0.25^{\circ}$. After preparing the early work, these specimens were loaded under uniaxial compression. Meanwhile, AE instrument was used to monitor.

This test adopted the axial displacement loading way and the loading speed was controlled at $0.005 \mathrm{~mm} / \mathrm{s}$. It is necessary to ensure that the loading machine and $\mathrm{AE}$ motoring system synchronously obtain the mechanical behaviors and AE characteristics under loading in real time.

The preamplifiers of $\mathrm{AE}$ were set at $40 \mathrm{~dB}$. AE testing system included 6 sensors for realizing real-time 3-D positioning of limestone samples during the entire deformation and fracture processes. Meanwhile, to reduce the influence of environment noise, the threshold value of PCI was set at $45 \mathrm{~dB}$ and the sampling rate was set at $1 \mathrm{MHz}$. To reduce the influence of end-effects, $6 \mathrm{AE}$ sensors were fitted on the limestone specimen $20 \mathrm{~mm}$ away from the top and bottom of specimens. Petroleum jelly and an adhesive band were used to fix the sensors on the specimen surface. To ensure that each channel normally collected signals, it was necessary to conduct the lead-break experiment near the $6 \mathrm{AE}$ sensors to verify that whether a good coupled relationship between sensors and the specimen.

\subsubsection{Define the TDF}

The nonlinear fracture and instability process of rock could be well described by the damage evolvement process. Therefore, in this chapter, the damage curves were used to analyze the fracture and instability process of limestone. Tangent damage factor (TDF) curves were used to predict rock failure. The damage evolvement process was regarded as the nonequilibrium statistical process. So the damage factor (DF) of rock follows statistical distribution. The statistical distribution of Weibull two-parameters was as follows: 


$$
\phi(F)=\frac{m}{F_{0}}\left(\frac{F}{F_{0}}\right)^{m-1} \exp \left[-\left(\frac{F}{F_{0}}\right)^{m}\right]
$$

where $F$ is the random distributed variable; $\phi(F)$ is the measure of micro-units damage; $m$ and $F_{0}$ are the distributed parameters, $m$ is parameter reacted the level of rock brittleness, $F_{0}$ is the macro average strength of rock.

DF reflects the damage degree of materials. Meanwhile, the damage degree is related to each defective micro-unit. These defects directly affect micro-units strength. The relationship between DF and the probability density of micro-units failure is as follows:

$$
\frac{d D}{d F}=\phi(F)
$$

Therefore, DF can be calculated as:

$$
D=\int_{0}^{F} \phi(F) d F=1-\exp \left[-\left(\frac{F}{F_{0}}\right)^{m}\right]
$$

Essentially, AE activity is consistent with the statistic distributed regularity of material internal defects. Therefore, AE count could reflect the distribution of damage. If the accumulated $\mathrm{AE}$ count is $\Omega m$ (ringing counts or energy counts) on the whole cross section completely destroyed, AE accumulation count could be expressed during the deformation and fracture process, as follows:

$$
\Omega=\Omega_{m} \int_{0}^{F} \phi(x) d x
$$

When $\Phi(\mathrm{x})$ is taken as the function (7.4), the expression (7.6) can be calculated as:

$$
\frac{\Omega}{\Omega_{m}}=1-\exp \left[-\left(\frac{F}{F_{0}}\right)^{m}\right]
$$

Comparing expression (7.6) with (7.7), it can get the damage expression caused by loading:

$$
\frac{\Omega}{\Omega_{m}}=D
$$

Therefore, the damage which is defined by AE parameters can be calculated by expression (7.8). In other words, the damage can be expressed by accumulated ringing counts or accumulated energy counts. 
The change process of DF could be used to describe the process of rock failure and establish the power law relationship between damage and time. It provides important information to identify the predicting key points of rock failure. Therefore, it is important to establish the power law relationship between damage and time. The previous derive the expression of damage with the Weibull statistics distribution theory and the strength equivalent hypothesis theory is as follows:

$$
D=1-\exp \left[-\frac{1}{m}\left(\frac{\varepsilon}{\varepsilon_{0}}\right)^{m}\right]
$$

where $D$ is damage variable; $m=\frac{1}{\ln \left[\frac{\varepsilon_{0}}{\sigma_{0}}\right]}$ and $\varepsilon$ are the shape parameters of rock; $\varepsilon_{0}$ is the peak strain. So it is easy to infer that DF is associated with the strain of limestone sample, the initial elastic modulus, the peak strain and the peak stress.

In the test, the stain of limestone is proportional to the loading time under the loading condition. The scaling factor of expression is $\frac{v}{h}$. So the relationship between strain and time of limestone is as follows:

$$
\varepsilon=\frac{v t}{h}
$$

The power law relationship can be obtained from Eqs. (7.9) and (7.10):

$$
D=1-\exp \left[-\frac{v^{m}}{m h^{m} \varepsilon_{0}^{m}} t^{m}\right]
$$

From Eq. (7.11), DF is associated with the loading speed, the shape and size and the peak strain. At the same time, DF has a power law relationship with the loading time. Based on DF, an expression of TDF was established. Assume that incremental damage value was $\Delta D$ and the correspondingly changing time value was $\Delta t$. TDF was calculated according to the incremental damage value $\Delta D$ and the correspondingly changing time value $\Delta t$. As follow:

$$
k_{D}=\frac{\Delta D}{\Delta t}
$$

where $\Delta D=D_{i}-D_{i-1}, \Delta t=t_{i}-t_{i-1}$. Based on the damage curves, in this chapter, the proposed the concept of TDF which could identify the predicting key points of rock failure rapidly and exactly. At the same time, it was helpful to realize in time predicting in the process of rock failure and provide important predicting information for rockbursts and other hazards.

Under the effects of loading and environment, rockmass damage is caused by the original material's micro-cracks and micro-holes. During the loading process, $\mathrm{AE}$ events are generated from the interaction of internal micro-cracks, expansion, linking and macro-failure within these samples. It is related to the evolution and development of cracks in the internal rock. The changes of AE events count are 
consistent with the damage evolution patterns of samples. Therefore, theories of damage mechanics can be used to establish evolvement models based on the characteristic parameters of $\mathrm{AE}$ in the rock failure process.

In this chapter, $\mathrm{DF}$ was introduced with $\mathrm{AE}$ parameters; the power law relationship was obtained between damage and time. Then, TDF was defined by the tangent curves of DF; it could be described the process of rock failure and identify the predicted key points. The graded predicting method was proposed in the process of rock failure. Finally, a damage-time-failure-predicting model was established.

According to the change of $\mathrm{AE}$ events count, which were consistent with the damage evolution patterns of rock, the DF was easily obtained, being defined by $\mathrm{AE}$ counts. AE damage degree was defined as the measure point divided by the total counts.

\subsubsection{Damage Characteristic of Limestone Failure}

Based on AE parameters of 6 specimens in the process of rock failure under uniaxial compression, DF curves were obtained, as shown in Fig. 7.12.

The correlation coefficients of samples X1, X2 and X6 were 0.99838, 0.9834 and 0.99599 , respectively. DF curves were presented the characteristic of 'rapid growth-stable growth-sharp growth-stability', which can well describe the process of rock failure. They had a more obviously phased change, such as X2, X4 and X5.

Based on the experimental data of two groups and the fitted results, DF value has well relationship with the loaded-time. The relationship of them is as follows:

$$
D=A_{2}+\frac{A_{1}-A_{2}}{1+\left(t / x_{0}\right)^{p}}
$$

All the expressions of above fitted DF and loaded-time are shown in Table 7.4. As presented in the first group, $x_{0}$ is directly correlated with the loaded-time. $A_{2}$ is closer to the peak point of DF value, while $A_{1}$ is near 0 . The power law relationship between $D$ and the loaded-time is from 1 to 3 . The power law equation between DF and the loaded-time for the first group is as follows:

$$
D=\left\{\begin{array}{c}
1.23176-\frac{1.20616}{1+(t / 446)^{2.37198}} \\
1.77072-\frac{1.76614}{1+(t / 93.63)^{1.89744}} \\
1.61395-\frac{1.54716}{1+(t / 60.05)^{1.55592}}
\end{array}\right.
$$

where $A_{1}$ is $0,1<A_{2}<2,1<p<3 ; x_{0}$ is the relationship with the loaded-time $t$ in the process of rock failure. Therefore, a damage model applied to the limestone 


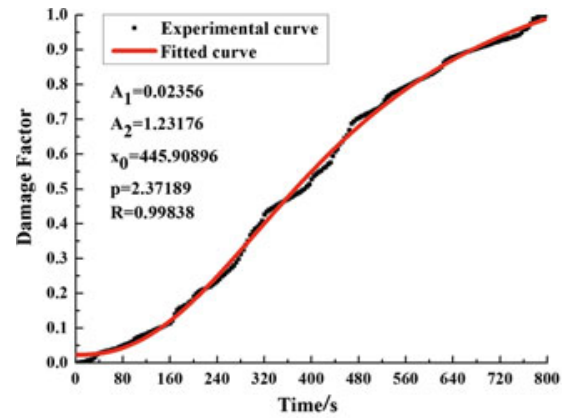

(a) $\mathrm{X} 1$

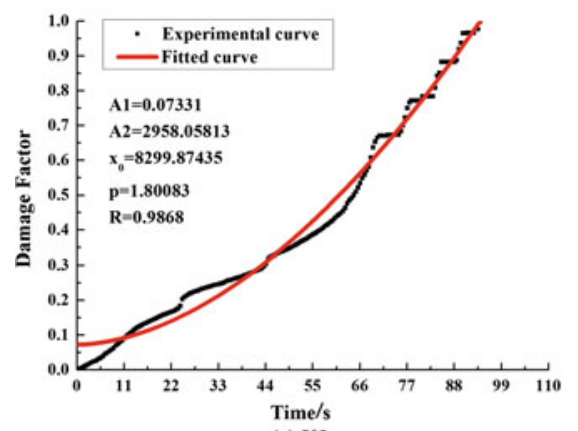

(c) $\mathrm{X} 3$

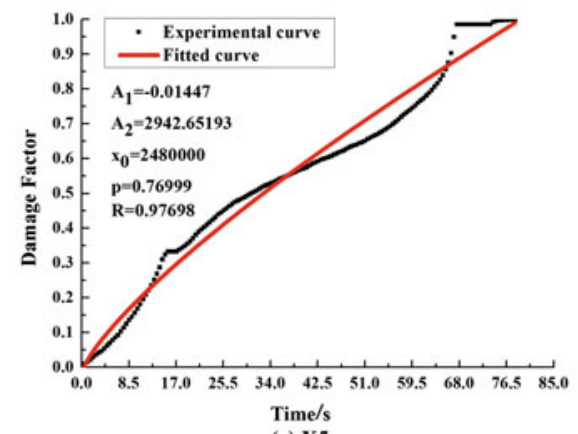

(e) X5

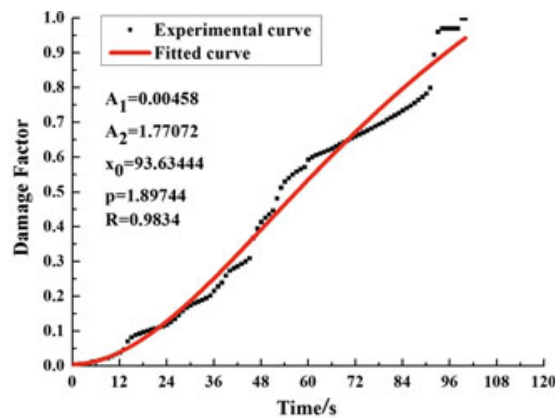

(b) $\mathrm{X} 2$

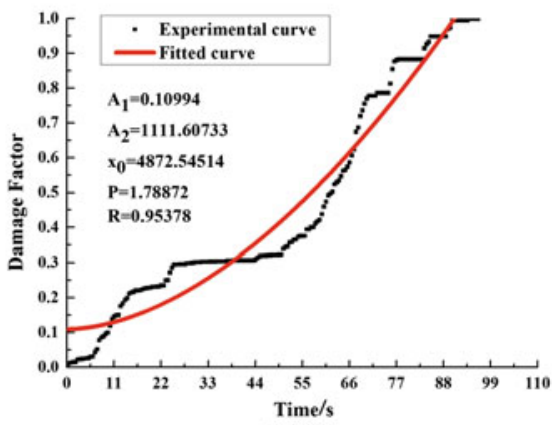

(d) $\mathrm{X} 4$

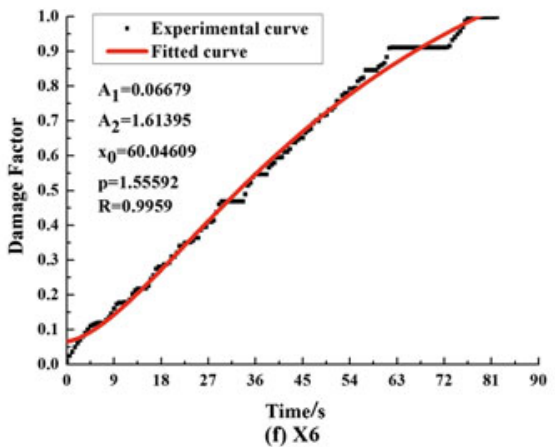

Fig. 7.12 The damage factor curves of samples

rock could be established. The loaded-time $t$ was viewed as a variable in the damage model, as follows:

$$
D=A_{2}\left[1-\frac{1}{1+\left(t / t_{0}\right)^{p}}\right]
$$

where $t_{0}$ is the loaded-time constant; $A_{2}$ is the material constant; $p$ is the power between DF and the loaded-time and is generally $1-3$. 


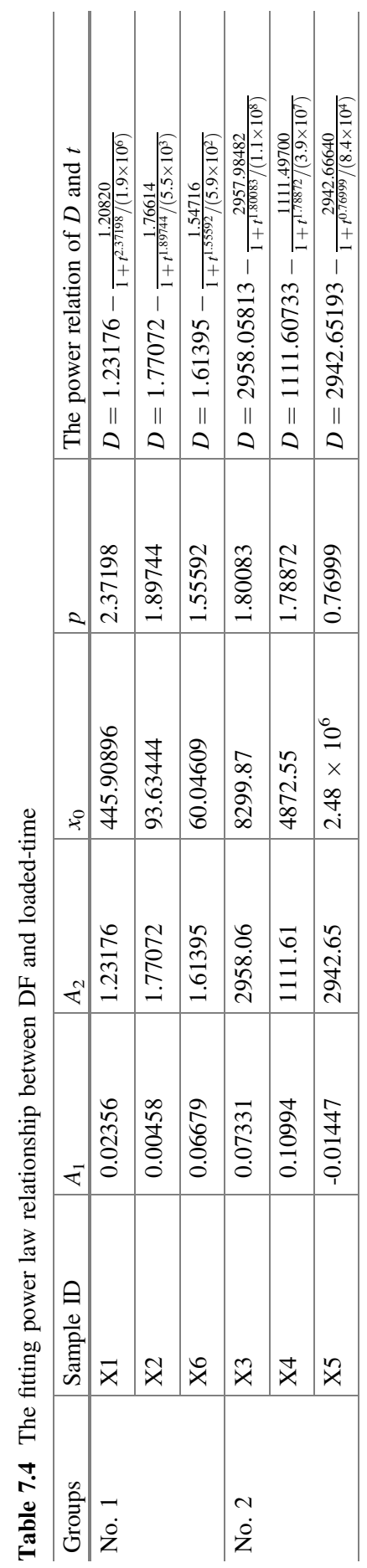


In this chapter, specimen $\mathrm{X} 5$ was selected to describe the experimental process of rock failure. TDF data is $\mathrm{k}_{\mathrm{B}}$ to 0 . The predicting data of sample X5 is as follows in Table 7.5 .

The damage curves have many phased grades, which could be used to describe the process of limestone failure. TDF curve is shown in Fig. 7.13.

Many ways could be used to define the DF, including the macroscopic perspectives and micro perspectives. In this chapter, DF was defined using AE counts. The proposed TDF was used to predict the rock failure. As shown in Fig. 7.12, DF curves and fitting curves of 6 limestone specimens were obtained. The fitting degree of samples showed the characteristic of phased with sharply rising in some phases. This phenomenon occured might because many natural joints existed in the limestone samples, which caused AE change. In the loaded process, the original joints were gradually closure, developed and merged, which caused AE ringing counts to increase sharply. DF curves of limestone samples presented the phased characteristic of rock failure.

As shown in Table 7.5, a power law relationship between DF and predicting time was presented; Predicting time could be inferred by using DF value. It could be used to estimate not only the nonlinear process of rock failure qualitatively but also the predicting time quickly. As shown in Fig. 7.13, the power law functions could be obtained based on the high fitted degree and the damage model (Eq. 7.14) had general applicability.

Table 7.5 The parameters of predicting points

\begin{tabular}{l|l|l|l}
\hline The predicting point item & Damage factor $(D)$ & TDF $(\mathrm{k})$ & The predicting time $(\mathrm{s})$ \\
\hline A & 0.325 & 0.022 & 14.50 \\
\hline B & 0.666 & 0.008 & 52.5 \\
\hline C & 0.980 & 0.023 & 67.5 \\
\hline D & 1.000 & 0.003 & 71.8 \\
\hline
\end{tabular}

Fig. 7.13 The tangent damage factor curve

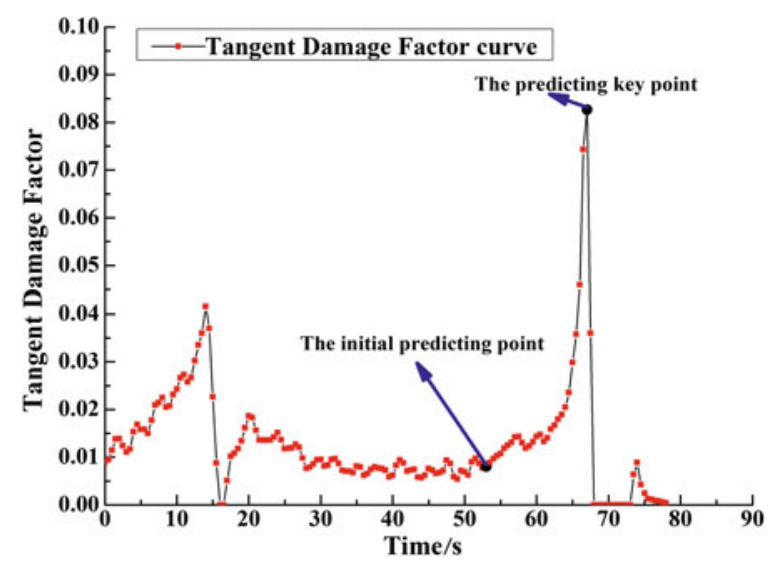




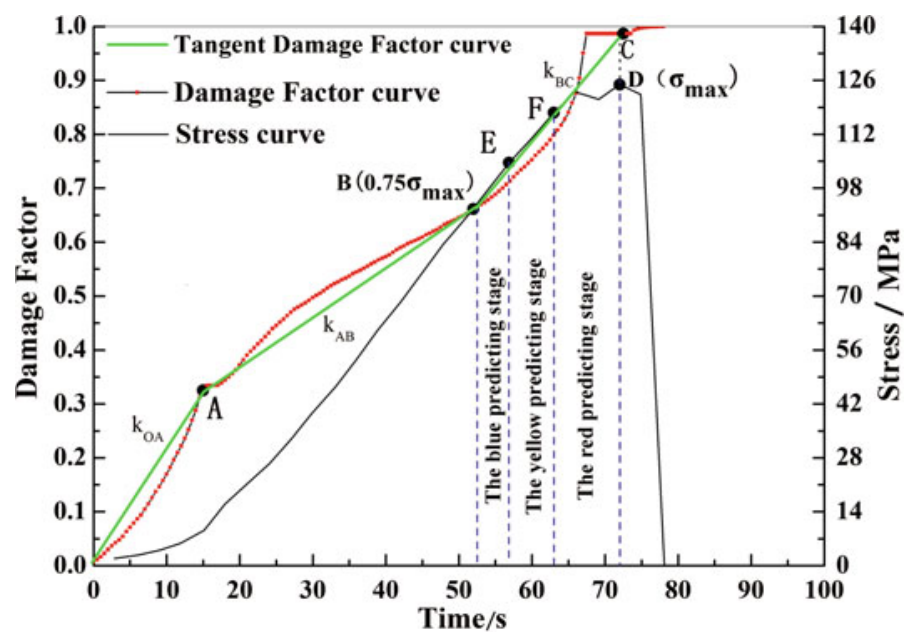

Fig. 7.14 The damage factor and the stress-time curve

The damage evolution characteristics were analysed using sample X5 as an example to analyze the process of rock failure. As shown in Fig. 7.14, DF and loaded-time curve of sample X5 were displayed. The evolution process of DF and loaded-time curves showed the characteristics of 'rapid growth-stable growthsharp growth-stability phased'. Therefore, the damage of pre-peak stress could be divided into four stages: the initial damage stage (OA), the continuous damage stage $(\mathrm{AB})$, the accelerated damage stage $(\mathrm{BC})$ and the stability damage stage.

(1) OA stage: DF curve corresponded to the original cracks compaction stage of stress-strain curve. The initial DF value of sample was 0 , and it rapidly increased because of obviously increased AE activities caused by the originally open micro-cracks. In this stage, DF curve had a concave shape. TDF increased gradually. As shown in Table 7.5, the slope of OA stage $\mathrm{k}_{\mathrm{OA}}$ value was 2.20, the slope of $\mathrm{AB}$ stage $\mathrm{k}_{\mathrm{AB}}$ value was 0.88 , and $\mathrm{k}_{\mathrm{OA}}>\mathrm{k}_{\mathrm{AB}}$. Therefore, point $\mathrm{A}$ was a turning point of DF value.

(2) $\mathrm{AB}$ stage: DF curve corresponded to the elastic deformation stage of stress-strain curve. In this stage, the straight line of DF value increased slowly because of less AE activity. TDF value had decreasing trend. However, it could be regarded as a constant. In this DF curve, point B was a sudden jump point of $\mathrm{DF}$, transitioning from the stable growth stage to the sharp growth stage. This characteristic, which was the sharp increase behaviour of TDF, was viewed as the predicting point of rock failure.

(3) BC stage: DF curve corresponded to the cracks growth of micro-damaging stage of stress-strain curve. In this stage, micro-cracks were generated constantly and cracks expanded rapidly. Meanwhile, AE activities increased significantly. 
DF value of BC stage increased more quickly than the OA stage. DF was a rising curve. TDF increases markedly. In Table 7.5, the slope of $\mathrm{BC}$ stage value $\mathrm{k}_{\mathrm{BC}}$ was 2.3 , and $\mathrm{k}_{\mathrm{BC}}>\mathrm{k}_{\mathrm{AB}}$.

(4) The latter stage: DF curve corresponded to the small part of failure stage of stress-strain curve. In this stage, the damage value remains nearly unchanged and TDF approximates zero.

\subsubsection{Predicting Models of TDF}

As shown in Fig. 7.14, in the compaction stage (OA), DF value of limestone sample increased markedly and $\mathrm{TDF} \mathrm{k}_{\mathrm{OA}}$ was relatively large. Then, in the liner elasticity stage $(\mathrm{AB})$, the DF value continued to increase, but there was a trend of slowing down. TDF $\mathrm{k}_{\mathrm{AB}}$ could be regarded as a constant. In this stage, the fracture of limestone sample did not occur. When DF value reached point B, and increased rapidly. The propagation and merged of cracks occurs. It would gradually develop until rock failure. Thus, point $\mathrm{B}$, the turning point from the stable growth stage to the sharp growth stage, could be regarded as the initial predicting point for the damage. When DF value exceeded point $\mathrm{C}$ to approaches 1 gradually, the limestone sample would begin to fail and become unstable. The peak point $\mathrm{D}$ in the curve was regarded as the predicting key point of rock failure. The identity of initial predicting point B was vital. Therefore, the initial predicting point could be identified based on the sudden change behaviour of TDF curve. As shown in Fig. 7.15, where a (14.5 s) was the first peak point of TDF curve; b (52.5 s) was the lowest point of TDF curve in the sudden rising process; $\mathrm{c}(66.1 \mathrm{~s})$ was the second peak point of

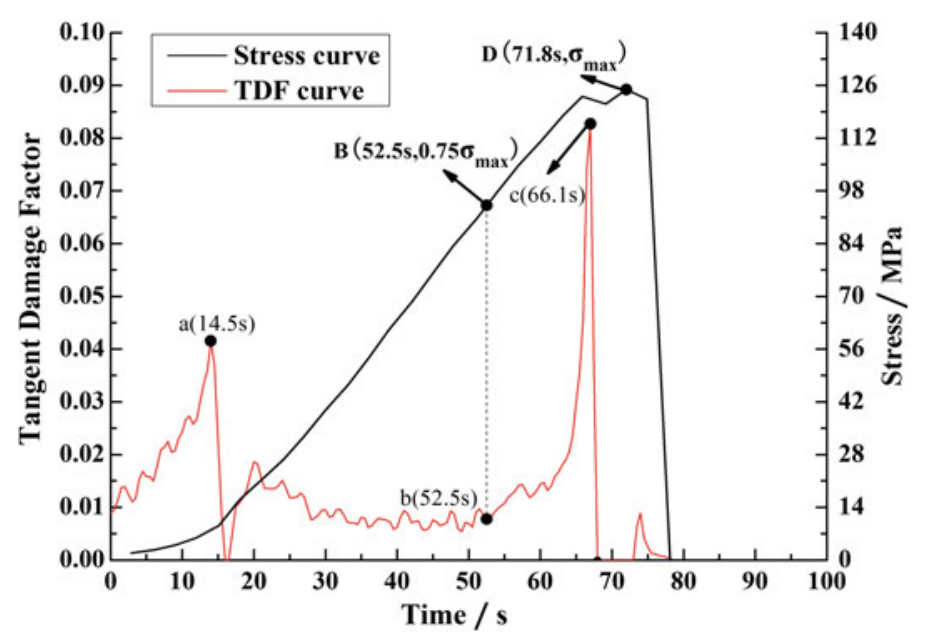

Fig. 7.15 Tangent damage factor and the stress-time curve 
TDF curve; $\mathrm{B}\left(52.5 \mathrm{~s}, 0.75 \sigma_{\max }\right)$ was the initial predicting point of stress curve corresponded the $\mathrm{b}$ point of TDF curve; D $\left(71.8 \mathrm{~s}, \sigma_{\max }\right)$ was the predicting key point of rock failure.

In the initial compaction stage, TDF increased markedly and eventually reached the peak point a $(14.5 \mathrm{~s})$. Then, it decreased sharply and finally reached the minimum point from 14.5 to $16 \mathrm{~s}$ in this period. That was also the transition phase of limestone for transiting from the original cracks compaction stage to the elastic deformation stage. After this stage, TDF tended to fluctuate steadily and the damage value increased more slowly. With the development of cracks, when TDF reached point b (52.5 s), TDF value increased sharply and was more markedly than that in the compaction stage. Finally, it suddenly jumped to peak point $\mathrm{c}(66.1 \mathrm{~s})$. Based on the loading time, point B of stress-strain curve could correspond to point $b$. The stress value of this point was $95.75 \mathrm{MPa}$, and it was approximately at $75 \%$ of peak strength. Point B was the sudden jump point for the DF value, transitioning from stable growth to sharp growth. It was the sudden jump point for transiting from the elastic deformation stage to the cracks growth of micro-cracking stage; the point $\mathrm{B}$ was defined as the initial predicting point. Beyond the TDF value point $\mathrm{c}$, TDF value decreased rapidly to 0 , eventually becoming smooth and steady. Based on the loading time, point $\mathrm{C}$ corresponded to the stress-strain curve. The stress value of this point was $125 \mathrm{MPa}$, and it was $98 \%$ the peak strength. The peak point $\mathrm{D}$ of stress-strain was defined as the predicting key point. Therefore, a damage-time-failure-predicting model was established based on the identification of TDF with the complete stress-strain curve. TDF, particularly, might play an important role in predicting rockburst.

To predict the failure of limestone more reasonably and accurately, time-divided predicting was proposed. Equal interval from the initial predicting point (B) to the predicting key point (D) was divided. TDF from $\mathrm{k}_{\mathrm{B}}$ to 0 was divided into three predicting stages: the blue predicting stage, the yellow predicting stage and the red predicting stage, which could yield the classification of predicting for limestone failure.

During the cracks growth of micro-damaging stage, when the stress was close to $90 \%$ peak strength, the micro-cracks, rock expansion and rock strain sped up. Meanwhile, the deformation of rock increased rapidly with the stress. Therefore, $0.917 \sigma_{\max }\left(\sigma_{\max }\right.$ is the compressive strength) was regarded as a predicting point. Based on the equal parting principle, stage BD was divided into three predicting stages, as shown in Fig. 7.14. The stage of B $\left(0.75 \sigma_{\max }\right)-\mathrm{E}\left(0.833 \sigma_{\max }\right)$ was the blue predicting stage; the stage of $\mathrm{E}\left(0.833 \sigma_{\max }\right)-\mathrm{F}\left(0.917 \sigma_{\max }\right)$ was the yellow predicting stage; the stage of $\mathrm{F}\left(0.917 \sigma_{\max }\right)-\mathrm{D}\left(\sigma_{\max }\right)$ was the red predicting stage.

As shown in Fig. 7.14, with the development of damage evolution, the damage value increased constantly. When the limestone was loaded to $52.5 \mathrm{~s}$ to reach the initial predicting point $\mathrm{B}\left(0.75 \sigma_{\max }\right)$, the limestone samples began to continuously generate cracks. The volume of limestone transited from the state of compression to the expansion and then reached the predicting point $\mathrm{E}$. The stage BE was defined as the blue predicting stage, which was the early stage of predicting, belonging to the transiting phase of elastic-plasticity. When exceeding the predicting point E, DF 
value had a small phase of sharply increasing until reached to the predicting point $\mathrm{F}$ $\left(0.917 \sigma_{\max }\right)$, which was defined as the yellow predicting stage. The stage EF was proposed as the middle predicting. When exceeding the predicting point $\mathrm{F}$, the speed of rock deformation increased quickly. Finally, the stress reached to the predicting key point $\mathrm{D}$. Therefore, the stress beyond the point $\mathrm{F}$ would enter the predicting key stage, and stage FD was defined as the red predicting stage.

\subsection{Experimental Investigation on Predicting Points Using Information Entropy Theory for Rock Failure}

\subsubsection{AE Dominant Frequency}

The Fast Fourier Transform (FFT) was proposed by Cooley and Tukey (1965). FFT is a type of fast computation method for the Discrete Fourier Transform (DFT). Based on the odd, even, imaginary, real and other characteristics of DFT, it is an improved form of DFT. FFT does not provide any findings different those of DFT. However, it substantially improves the arithmetic speed and efficiency of DFT, which is greatly useful for applying the DFT in a computer or digital system. In this chapter, FFT analysis was performed for all waveforms generated during rock failure, and the dominant frequencies were obtained. Sample X3 was used as an example to illustrate. The relationship between time-loading curves and dominant frequencies for the limestone sample was shown in Fig. 7.16.

The dominant frequencies of samples were obtained, and there were the following several characteristics:

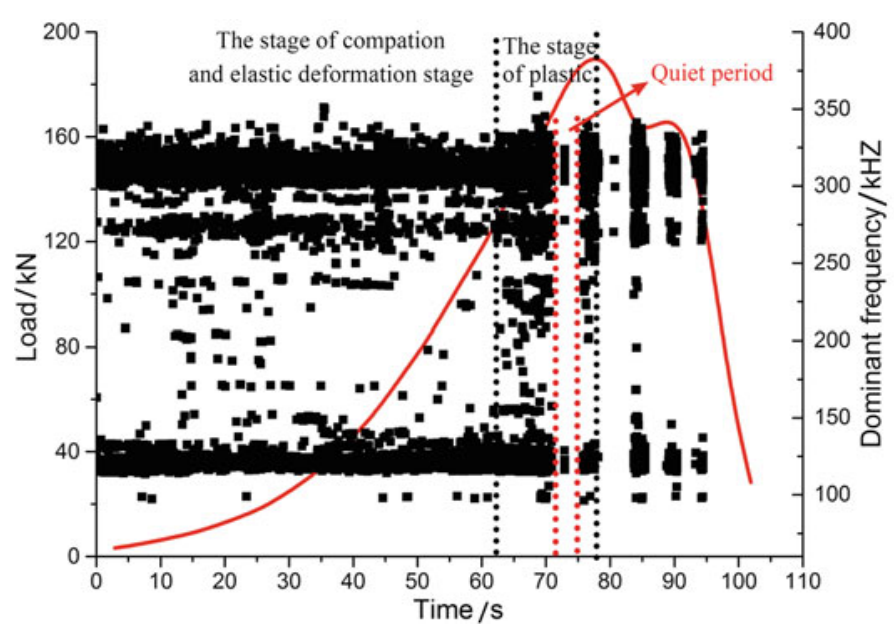

Fig. 7.16 Relationship between time-loading curves and dominant frequencies 
Table 7.6 Detail of dominant frequencies of sample X1

\begin{tabular}{l|c|c}
\hline Range $(\mathrm{kHz})$ & Amounts $(\mathrm{N})$ & Amount percentage $(\%)$ \\
\hline$[96.25,358.375]$ & 13,106 & 100 \\
\hline$[110,130]$ & 5231 & 40 \\
\hline$[275,340]$ & 6720 & 51 \\
\hline other & 1155 & 9 \\
\hline
\end{tabular}

(1) The sample had two frequency bands. The low-frequency band was at approximately $100-150 \mathrm{kHz}$, and the high-frequency band was at approximately $300-350 \mathrm{kHz}$.

(2) The high and low frequency bands of samples were generated simultaneously during the whole process of rock failure.

(3) With increasing load and deformation, the signals between two dominant frequency bands tended to increase.

Cai et al. (2007) noted out that the high-frequency band of AE corresponds to small-scale cracks, whereas the low-frequency band corresponds to large-scale cracks. Therefore, the change in the frequency bands indicated that rock deformation and failure involved a process of micro-crack initiation, propagation and linking. The dominant frequency distributions of rock sample had common characteristics.

As shown in Fig. 7.16, the dominant frequency distribution of the whole rockburst process was related to stress levels. In this chapter, the relationship between stress and frequency distribution characteristics was analysed based on sample X3. The range of dominant frequency values for the sample was 96,250 $358,375 \mathrm{~Hz}$, as shown in Table 7.6. In the rock compaction and elastic stages, the dominant frequencies were concentrated into two frequency bands, a low-frequency band of $110-130 \mathrm{kHz}$, and a high-frequency band of $275-325 \mathrm{kHz}$. In the plastic stage, the distribution of dominant frequencies in the two dominant frequency bands was more intensive, indicating that the cracks developed more rapidly. A large number of AE signals were released in this process. At the same time, numerous dominant frequency values appeared between two dominant frequency bands; the frequencies entered the broadband phase at this time. A complex AE rupture source was caused by the unstable propagation of cracks. The sample changed from comprising a single rupture source to comprising a variety of rupture sources. Meanwhile, it was observed that sample X3 had an obvious quiet period at $71-76 \mathrm{~s}$; stress was at $88.2 \%$ of the peak strength (Fig. 7.16). This phenomenon could be used as precursor information for rockburst.

\subsubsection{AE Dominant Frequency Entropy}

The dominant frequency entropy values were calculated based on Eq. (3.5). The relationships between load-time curves and the dominant frequency entropy values 


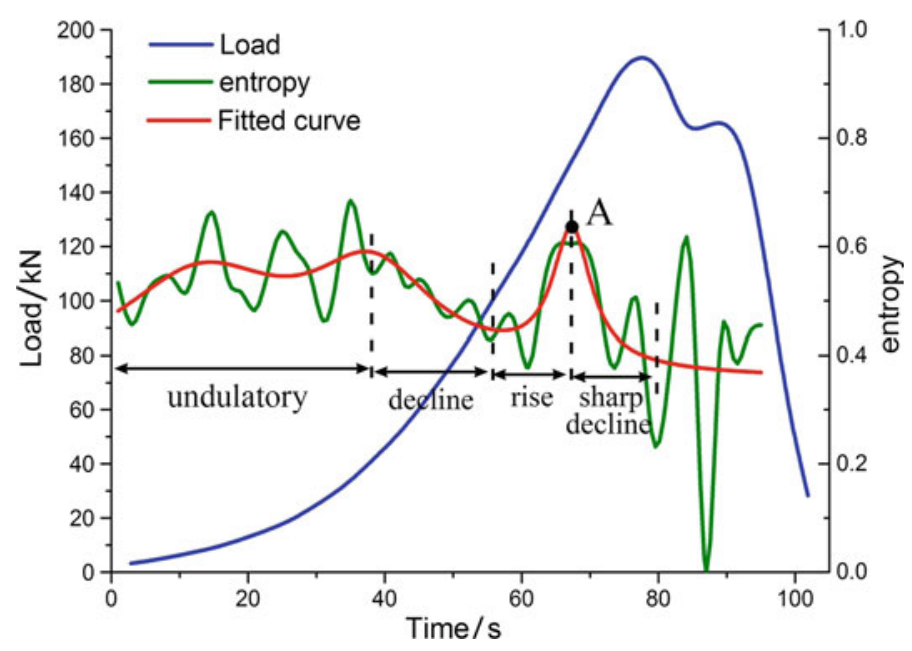

Fig. 7.17 Relationship between time-loading curve and entropy for sample X3

for the limestone samples were shown in Fig. 7.17. The dominant frequency entropy of sample exhibited the following characteristics: (1) The dominant frequency entropy values were between 0 and 1. (2) All of curves were in fluctuation. As shown in Fig. 7.17, the curve of sample X3 was fluctuating during the beginning of load, during the time interval between 0 and $38 \mathrm{~s}$. The disordered AE signals were mainly generated in the cracks compaction stage. With increased loading, the micro-cracks were generated in order. Therefore, the entropy curve was declined from 38 to $60 \mathrm{~s}$. Then, the curve appeared to rise slightly within the time interval between 60 and $69 \mathrm{~s}$. The continued generation of disordered AE signals was caused by micro-fracture formation. Then the micro-cracks initiated, propagated, and merged progressively into a macro-crack. Therefore, the entropy value decreased sharply in the time period from 69 to $78 \mathrm{~s}$. Therefore, the evolution model of sample X3 was 'wave-decline-small rise-sharp decrease'. The entropy evolution model of sample X3 illustrated that rockburst was a process of initiation and propagation of multiple cracks into a macro-crack. Meanwhile, these processes were synchronous.

\subsubsection{AE Dominant Frequency and Entropy}

Based on all collected AE waveforms, we calculated the dominant frequency values using the method of FFT spectrum analysis, and analyzed their distribution characteristics during rock failure. In the crack compaction and elastic deformation stages, these results showed that the distribution of dominant frequencies was concentrated into two frequency bands. Then, in the unstable crack propagation 
stage, the dominant frequencies were in the broadband range. Rock failure evolved from a single rupture source to a variety of rupture sources. For frequency evolution, several studies were studied. With the experiments in the laboratory and situ, Lu et al. (2012b) found that precursory AE (MS) signals was showed at tendency for the spectrum to move to the low-frequency band. Aftershock signals had spectra moving to the high-frequency band. Moreover, there was a negative relationship between predominant frequency of main shock signal and rockburst failure intensity. Bakker et al. (2016) performed AE experiment under triaxial compression in the laboratory, and found that low-frequency signals were generated during rock specimen failure because of movement of viscous fluid through cracks. Most prior studies were based on frequency distribution characteristics. Few studies focus on evolution models and the possibility of predicting rockburst using information entropy. In this chapter, based on the theory of information entropy, we further investigated the dominant frequency evolution during the overall process of rock deformation and failure. Meanwhile, information entropy evolution models were investigated. Notably, the entropy evolution followed the decreased pattern of wave rise-sharp. In order to better analyze information entropy evolution pattern, the curves of entropy evolution were fitted in Fig. 7.17. The phenomenon, when information entropy dropped sharply before rock failure, could be more intuitive to observe. Meanwhile, the entropy appeared at a maximum value, as shown at point A (Fig. 7.17). The maximum value point A appeared near the yield point. Then, the information entropy value decreased sharply. The change occurred synchronously with micro-crack merger and macro-crack formation. For the entropy value variation, in the author's opinion, the dissipative structure theory could explain this phenomenon. Prigogine (1969) pointed out that in an open system at a nonlinear region far from equilibrium, there would be continuous exchange of matter and energy with the external environment, and the system would undergo mutation when the external environment reached a certain condition, that was a nonequilibrium phase transition from disordered chaos into an ordered state of time, space or function. In the stage of compaction and elastic deformation stage, there was no macroscopic irreversible process inside the system, which was a balanced state. The information entropy presented wave variation. In the stable growth crack stage, the cracks stopped developing. After a certain time, the system might reach a macro state that did not change over time, was a nearly equilibrium state. In the unstable crack propagation stage, the cracks developed even though stress remained constant. As the micro-rupture expansion was a spontaneous dynamic process, the system was far from the equilibrium state. On one hand, the system absorbed energy from the outside; On the other hand, the system released energy because of cracks development. The macroscopic status of system changed with time, and the distribution of microcracks in the space was localized, that is, a phase transition from the disorder to ordered status. The entropy sharply decreased at this time. The dissipative structure was formation. With stress continuous increase, AE dominant frequencies changed from disordered chaos into an ordered status after stress reached point A. Therefore, the entropy value decreased sharply. Then, the loading 
of rock specimens entered the unstable cracks propagation stage. Micro-cracks propagated, merged progressively, and finally formed macro-cracks. The entropy value decreased sharply, which might provide precursory information for prediction rockburst. Therefore, we used point A as predicting key point of rockburst.

\subsection{Predicting Key Point Identification Using Traditional Monitoring Method}

In order to further study on predicting key point of rockmass deformation and failure, we analyzed the monitoring data of rockmass deformation from the stress-strain curve. However, how to analyze the development of plastic deformation by mechanical parameters is a question worthy of study. In this chapter, an instability predicting model and method was built using Tangent modulus. Meanwhile, this model was applied to Huize lead-Zinc Mine in China, which shows greater adaptability.

\subsubsection{Methods for Instrument Installation and Data Collection}

The detailed process to set up predicting methods for rockmass instability is as follows:

(1) Determine the monitoring and predicting area of rockmass, partitioning and numbering them. To get a distinct monitoring network, numbers correspond to the change of incremental stress and incremental displacement.

(2) Drill hole for stress and displacement monitoring. The bottom of drilling hole for stress monitoring should be located in the rockmass that was easy to produce instability and it cannot be located in the virgin of rockmass. The deepest anchor point of borehole for vibration twist-action multipoint displacement instrument should be located in the virgin of rockmass.

(3) Construct the borehole in the direction vertical to the excavation face according to the radial size of vibration twist-action multipoint displacement instrument. The drilling length should be more than 3 times the radius of excavation space. In general, the diameter of borehole is $45-76 \mathrm{~mm}$. Record the drilling length as $\mathrm{L}$ and the displacement value as $\Delta l$ (with units in $\mathrm{mm}$ ). The deepest displacement monitoring points should be located in the region of initial stress. The measurement range of multipoint displacement instrument is $0-20 \mathrm{~mm}$ with an accuracy of $0.2 \mathrm{~mm}$ and sensitivity of less than $0.01 \mathrm{~mm} / \mathrm{F}$. To master the strain change status in rockmass failure, the temperature measurement range is -40 to $140{ }^{\circ} \mathrm{C}$ with an accuracy of $\pm 0.50{ }^{\circ} \mathrm{C}$, the water pressure resistance is greater than 
$1 \mathrm{MPa}$, insulation resistance is greater than or equal to $50 \mathrm{M} \Omega$ and the anchor point numbers of about 3-5. Meanwhile, in order to master the deformation of rockmass, the deepest anchor point of multipoint displacement instrument should be located in the virgin of rockmass, the rest of anchor points evenly distributed in drilling hole.

(4) Install vibration twist-action multipoint displacement monitoring instruments, grouting, anchoring and installing the base of measuring head, displacement sensor and protection sleeve, lengthening the cable.

(5) Install the sensors. The direction of stress monitored by borehole stress monitoring instruments should correspond with the direction of displacement monitored by multipoint displacement monitoring instruments. After frequency stabilization (about $10 \mathrm{~min}$ ), the sensor frequency was record at this time as the initial frequency and input this data into the monitoring instruments as the zero point. Then, the monitoring instruments directly reported the incremental stress.

(6) Set the parameters of borehole stress monitoring instruments and vibration twist-action multipoint displacement monitoring instruments, connecting the borehole stress monitoring instruments and multipoint displacement monitoring instruments to the computer, analyzing the incremental stress and strain.

\subsubsection{Recognition Method of Predicting Hazards}

The author proposed that Tangent modulus is the slope of each point on the stress-strain curve. When rockmass is loaded, in the stage of elastic, Tangent modulus is equal to elastic modulus; in the inelastic stage, Tangent modulus reduces quickly. Tangent modulus is calculated as stress variation and strain variation ratio. Generally, rockmass is considered to be elastic-brittle material. Meanwhile, stress-strain curve for rockmass is nonlinear. Tangent modulus could be used to describe the macro modulus of inelastic stage. Therefore, based on the change of Tangent modulus in the yield area, the degree of rock deformation is determined and the predicting key point for rockmass failure is recognized.

In this chapter, the detail recognition process of predicting hazards is as follows:

(1) The incremental strain $\Delta \varepsilon$ value was got using the incremental displacement value $\Delta l$ and the deepest drilling anchor length $\mathrm{L}$. Based on the incremental stress value $\Delta \sigma$ and the incremental strain value $\Delta \varepsilon$, Tangent modulus $E_{t}$ was calculated by the following expression:

$$
E_{t}=\Delta \sigma / \Delta \varepsilon
$$

(2) According to the constitutive relation of force in rockmass, the change of Tangent modulus slope $k$ was used to predicting the rockmass failure. When Tangent modulus slope invariant or increases, which could infer that rockmass was in the compression or elastic phase and rockmass instability did not occur; 
When tangent modulus slope decreases, which indicated the rockmass was in the yield stage and the initiation, expansion, connection of secondary cracks occured, all of which leaded to rockmass failure. Thus, the inflection point, where Tangent modulus slope $k$ decreased, could be defined as the predicting key point for rockmass failure. That was the predicting recognition method for rockmass instability. The specific application of this method was presented in Chap. 9.

\section{7 b Value Characteristics with MS Activity in Deep Mining}

The dynamic hazard of mine refers to the rockburst, rock falling and other disasters, which is caused by rock stress field during mine operation. Stress concentration leads to rockmass failure because of initiation, development, merged, and rupture of micro-rupture, then micro-seismic (MS) event generates in the fracture process. In monitoring and predicting the dynamic hazard of mine, MS and AE monitoring are the basic methods. These methods are widely used in the excavation of deep mine.

Using MS monitoring system, the random variable parameter in one-group MS events can be obtained at a certain monitoring area in a period time, and the magnitude-frequency relation can be determined to analyze the characteristics of $b$ value. By MS monitoring, the status of micro-rupture distribution, the potential area of dynamic hazard in mine could be concluded and for which we can make a prediction in advance. Therefore, to identify the relation of $b$ value with rockmass failure and instability can help us to know the characteristic of precursory MS parameters produced by rockmass failure and provide a basis for mine safety production.

\subsubsection{The Magnitude-Frequency Relation-b Value}

Many experiments showed that MS event generated by mining excavation follows the Gutenberg-Richter criterion, as shown in Fig. 7.18. By analyzing the MS activity, the magnitude-frequency relation is suitable for all magnitude range. In the time interval $[a, b]$, there is an exponential relationship between the frequency and magnitude at a MS monitoring area as follows:

$$
n(M)=N_{0} \mathrm{e}^{-b M}
$$

In general, the logarithmic function form was put forward as follow: 
Fig. 7.18 Relationship between number of events and magnitude. From Gutenberg and Richter (1956)

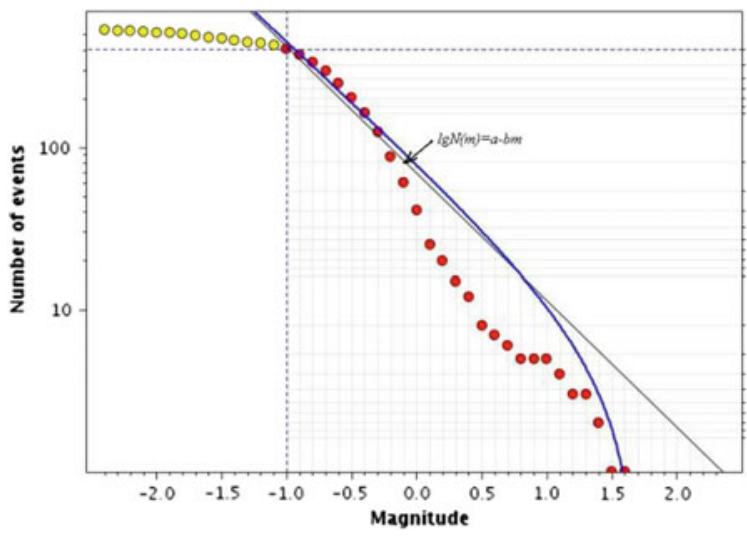

$\lg n(M)=a-b M$

where $a$ and $b$ are the unknown constants at a certain monitoring area; Constant a reflect the overall level of MS activity in this area and is viewed as MS activity parameter, which is correlated with the total MS events above the threshold magnitude; Constant $b$ describes the magnitude distribution of MS events, i.e., the relative number of small and large MS events in a certain time. Generally, $b$ value is close to 1 .

\subsubsection{Changes of b Value Caused by Rockmass Excavation}

$b$ value can reflect the proportional relationship of small and large earthquake events. The physical definition is that the change of $b$ values in one monitoring area, which means the degree of rock damage. The precondition is that $b$ values in this area have the unified monitoring capacity in a period. And the same earthquake magnitude above the lower limit magnitude could be monitored in the whole area. The change of $b$ values is correlated with the entire process of earthquake activity.

In the $8 \#$ orebody, the geology condition is very complicated with well developed faults and fragile rock-mass. Therefore, the dynamical hazard is easily occured during the stoping process. Because the stoping at the $1451 \mathrm{~m}$ level has overed, the 1331 and $1391 \mathrm{~m}$ levels are on upward stoping. The $1331-1451 \mathrm{~m}$ in the $8 \#$ orebody is the important area for stoping. The records of serious collapse caused in stope from August to December, 2007, were listed. Through the MS monitoring system, the parameters of MS events are obtained such as monitoring time, magnitude, $b$ value and the maximum magnitude, etc. The weekly $b$ values were recorded from August, 2007 to December, 2007 and listed. The specific application of this method is presented in Chap. 9. 
In conclusion, the value characteristics of $b$ can explain the dynamic hazard such as rockburst, stope roof fall, spalling. They provide an important role for predicting the rockmass instability, forecast accuracy and the improvement of safe work environment.

\subsection{Identification of Predicting Key Point Using AE/MS Monitoring System}

In laboratory experiment, the different variations of AE activity were obtained in different stress status. There were large difference between the performance characteristics of stress-strain variations and $\mathrm{AE}$ event activity rate. As shown in Fig. 7.19, in the compaction stage of initial damage, AE events were obviously increased and in an active state. However, the energy and magnitude of AE events were not sufficient to destroy the specimen. In the elastic stage, few AE events were produce, even tended to zero, which molecules and atoms were dislocated by force within the sample. When the stress reached the yield point, AE events increased dramatically, and then a relatively quiet period occurred. A large number of AE events would appear as a sharp increase in the peak strength until rockmass failure, unlike the quiet period. Therefore, a sharply decrease of AE events was used as the predicting point of rock failure, which did not indicate that rock instability was immediately obvious, but rock had entered the stage of cracks propagation. Rock damage status could be predicted with the further monitoring. In this chapter, the starting points of quiet period for AE events were determined as the predicting key points for the rock rupture and instability, which indicated the increase of rock

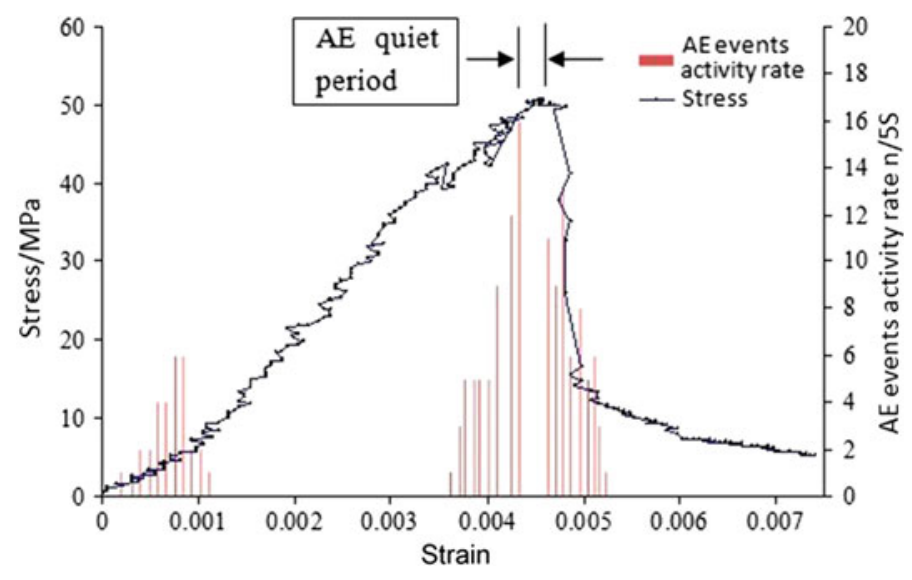

Fig. 7.19 The relationship between AE activity rate and stress-strain curve of rocky elastic-plastic materials. With kind permission from "PERGAMON-ELSEVIER SCIENCE LTD": Fig. 1, Wang (2014). All rights reserved 


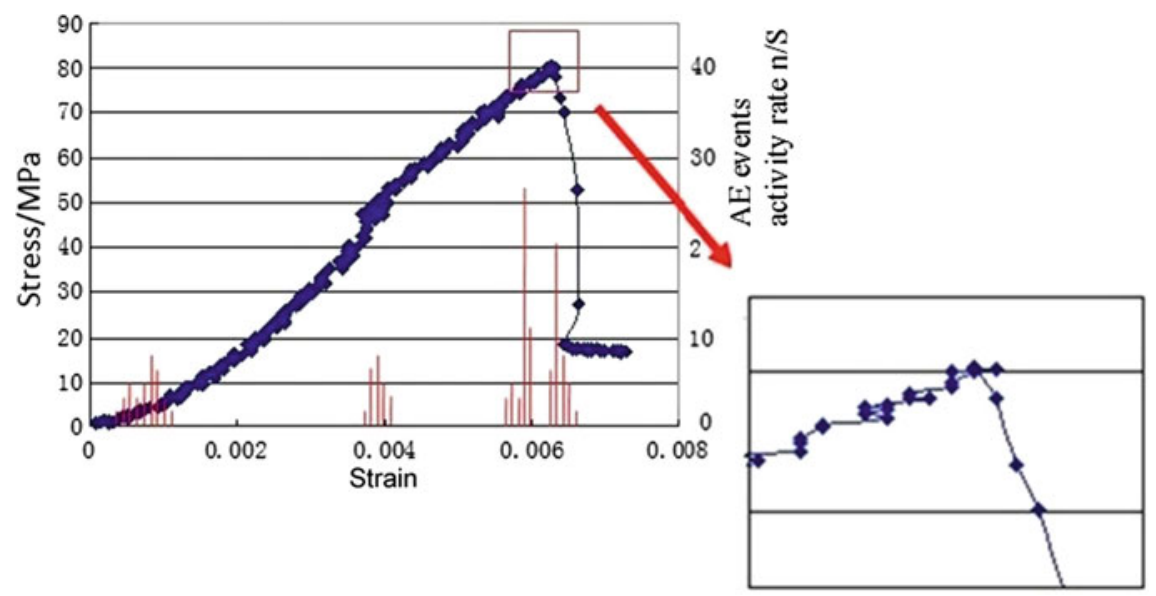

Fig. 7.20 The relationship between AE activity rate and stress-strain curve of rocky brittle materials. With kind permission from "PERGAMON-ELSEVIER SCIENCE LTD": Fig. 2, Wang (2014). All rights reserved

failure risk. With the increase of stress, the specimen would quickly enter a relatively stable period of AE events, which tended to be undermined. As rock sample is elastic-plastic material, the compaction and plastic stages were obvious in the deformation process. The time of AE quiet period is about $15 \mathrm{~s}$, which is relatively long. AE events appear the form of foreshocks-main shock-aftershocks. The predicting key points of rock failure could be easily identified by AE/MS monitoring system.

As rock is brittle material, it may be not easy to recognize the compaction and plastic deformation stages. Only a small deformation resulted in destruction and instability. Therefore, AE events, throughout the yield point, did not clearly and rapidly increase to enter the stage of rock instability and failure. Indeed, AE events exhibited mainshock-aftershock behavior. The predicting key points of this rock type were not easily identified by AE/MS monitoring, that is, the time of AE quiet period is about $2 \mathrm{~s}$, and it is relatively short and be easily lost, as shown in Fig. 7.20.

The main reason of $\mathrm{AE}$ relatively quiet period may be rock heterogeneity and particle distribution. When rock was loaded at the compaction stage, the nature cracks were compacted and a large number of small magnitude and low energy AE activity were appeared. Rock grains reached a status of balance. Then, rock reached the stage of elastic and a relative few stable AE activity. Under the constant load, new cracks were generated and propagated, which caused macro-cracks and a lot of great magnitude and high energy AE activity. Rock grains achieved another state of balance with the occurrence of AE quiet period before failure. When the balance of rock grains was broken again, rock achieved the peak strength and instability soon. The specific site application of this method is presented in Chap. 9. 


\subsection{Model of Multi-means and Synergistic Prediction for Rockburst}

In this section, we comprehensively consider several types of rockburst predicting methods mentioned in Sects. 7.2-7.8. Based on loading system, infrared radiation monitoring system and acoustic emission monitoring system, we designed the test system of rock failure to realize multi-means and synergistic prediction for rockburst. The test system is shown in Fig. 7.21.

As shown in Fig. 7.21, (1) Load/unload test system: load/unload the rock samples to obtain the stress-strain whole process curve and its corresponding data; (2) AE/MS monitoring system: synchronized with the load/unload process to monitor the process of rockburst, and obtain $\mathrm{AE}$ activity rate, energy, frequency and other AE parameters data; (3) Infrared radiation monitoring system: synchronized with the load/unload process to monitor the infrared thermogram change and record the infrared temperature data in whole rockburst process.

The model of multi-means and synergistic prediction for rockburst was shown in Fig. 7.22. All these methods, such as the infrared radiation temperatures, tangent modulus, load/unload response ratio and other ways; could effectively realize the prediction of rockburst. However, it was easy to misjudge, delay the information

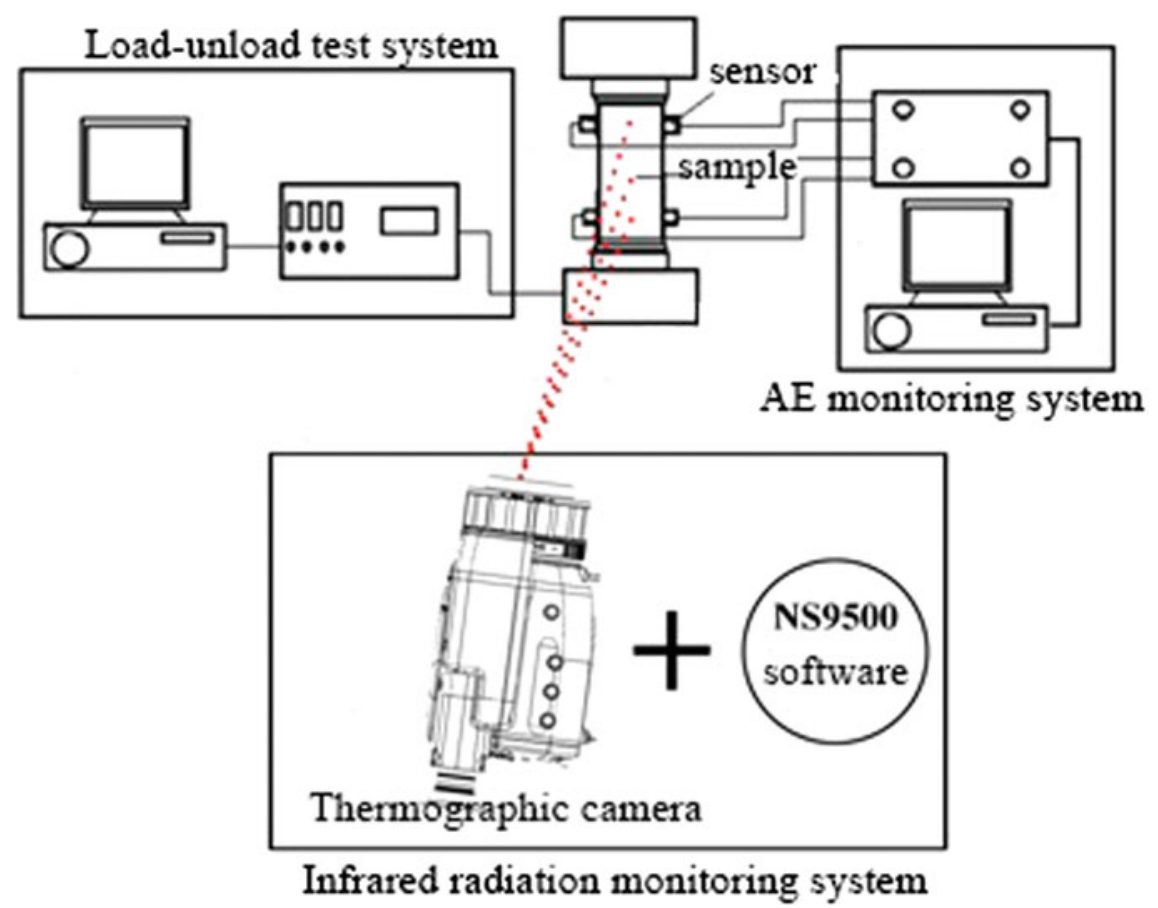

Fig. 7.21 Test system for coal failure synergetic prediction 


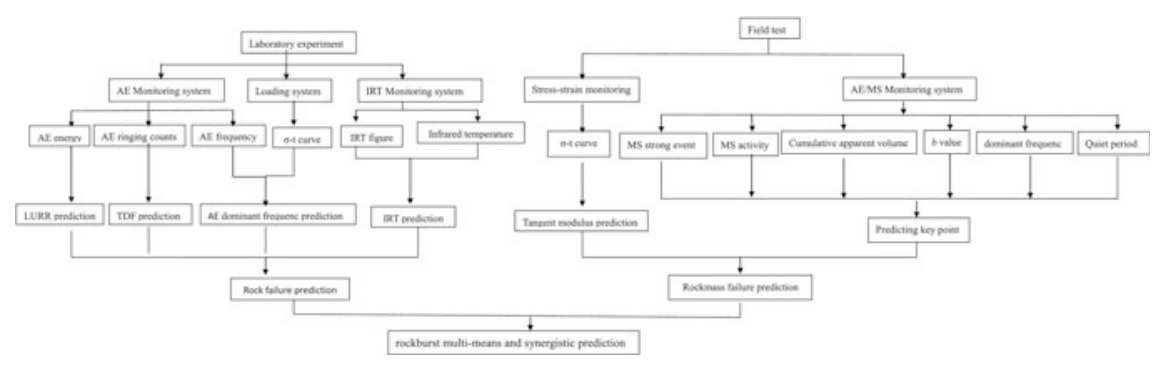

Fig. 7.22 Synergetic prediction for rockburst

and other issues using a single way to predict rockburst. The multi-means and coordinated synergistic prediction could make up for each other and verify each other, making it more reasonable, scientific and effective.

\subsection{Conclusion}

In this chapter, in view of single, hysteretic and poor effect prediction methods, we studied on the precursor information of rockbust using routine monitoring, infrared monitoring, AE/MS monitoring and other monitoring ways. The following conclusions were obtained:

(1) In the experiment, the mean temperature abnormality of "rising-dropping and rising" was observed in the later period of plastic deformation stage and could be suggested as the IRR precursor for rock failure. Meanwhile, the mean temperature increment interval of "dropping-rising" could be used as a predicting point for the coal failure.

(2) Based on the analysis of LURR evolution, LURR ratio $Y=1$ could be considered as the predicting point for rock failure.

(3) Based on TDF method, the sudden jump point, with respect to transiting from the state of stability to the state of rapid increase, was defined as the initial predicting point for the TDF. The peak point $\mathrm{C}$ was provided as the initial predicting point of red predicting stage for the TDF rapidly increasing peak point. The peak of stress-strain curve was defined as the predicting key point, the TDF value of which is 0 .

(4) The information entropy evolution models were a process of 'wave rise-sharp decrease'. The information entropy appeared at a maximum value before rockburst, and the maximum value was near the yield point. Then, the information entropy value decreased sharply, which could be viewed as a precursor of rockburst. Thus, the maximum value point could be used as a predicting key point for rockburst. 
(5) Based on the suddenly decrease of Tangent Modulus when the constitutive relation of rockmass came into the yield stage, the drop point of Tangent Modulus could be viewed as a precting key point for rock failure when rockmass passes through the elastic phase.

(6) MS activity parameters $b$ was sufficient and necessary conditions of rockmass failure. However, with the progress of mining and the increase of rockmass stress, it was important to grasp the patterns of MS activity parameters $b$ in the whole process of rockmass failure. This method could be used to predict dynamic disasters in deep mining.

(7) In the compaction stage, the low-magnitude and low-energy of MS events increases, and the high-magnitude and high-energy MS events sharply increased in entering the yield point. When MS events entered the relative quiet period, the predicting key point was identified as this position which indicated that the rockmass would increase the risk of rock instability.

(8) Based on predicting methods above mentioned, the multi-means and coordinated synergistic predicting method were designed, which made rockburst prediction more reasonable, scientific and effective.

\section{References}

Bakker RR, Fazio M, Benson PM, Hess KU, Dingwell DB (2016) The propagation and seismicity of dyke injection, new experimental evidence. Geophys Res Lett 43(5):1876-1883

Benson PM, Vinciguerra S, Meredith PG, Young RP (2010) Spatio-temporal evolution of volcano seismicity: a laboratory study. Earth Planet Sci Lett 297:315-323

Blake W, Hedley DGF (2003) Rockbursts: case studies from North American hard-rock mines. SME, Englewood, USA

Boltzmann L (1884) Ableitung des Stefan'schenGesetzes, betreffend die Abhängigkeit der Wärmestrahlung von der Temperaturaus der electromagnetischen Lichttheorie. Ann Phys 258:291-294

Brady BT (1969) The nonlinear mechanical behavior of brittle rock part I-stress-strain behavior during regions I and II. Int J Rock Mech Min Sci Geomech Abstr 6:211-225

Cai M, Kaiser PK, Morioka H et al (2007) FLAC/PFC coupled numerical simulation of AE in large-scale underground excavations. J Rock Mech Min Sci 44(4):550-564

Carpinteri A, Lacidogna G (2008) Acoustic emission and critical phenomena: from structural mechanics to geophysics. CRC

Carpinteri A, Lacidogna G, Niccolini G (2006) Critical behaviour in concrete structures and damage localization by acoustic emission. Key Eng Mater 312:305-310

Cook NGW (1992) Natural joints in rock: mechanical, hydraulic and seismic behaviour and properties under normal stress. Int J Rock Mech Min Sci Geomech Abstr 29:198-223

Cooley JW, Tukey JW (1965) An algorithm for the machine calculation of complex Fourier series. Math Comput 19(90):297-301

Cui CY, Deng MD, Geng NG (1993) Rock spectral radiation signatures under different pressures. Chin Sci Bull 38:1377-1382

Freund FT, Takeuchi A, Lau BWS et al (2007) Stimulated infrared emission from rocks: assessing a stress indicator. eEarth 2(1):7-16

Geng NG, Cui CY, Deng MD (1992) Remote sensing detection on rock fracturing experiment and the beginning of remote sensing rock mechanics. Acta Seismol Sin 14:645-652 
Genzano N, Aliano C, Filizzola C et al (2007) A robust satellite technique for monitoring seismically active areas: the case of Bhuj-Gujarat earthquake. Tectonophysics 431(1):197-210

Gutenberg B, Richter CF (1956) Magnitude and energy of earthquakes. Ann Geofis 9:1-15

He M, Miao J, Feng J (2010) Rock burst process of limestone and its acoustic emission characteristics under true-triaxial unloading conditions. Int J Rock Mech Min Sci 47:286-298

He MC, Zhao F, Zhang Y, Du S, Guan L (2015) Feature evolution of dominant frequency components in acoustic emissions of instantaneous strain-type granitic rockburst simulation tests. Rock Soil Mech 36(1):1-8 (in Chinese)

Kukshenko V, Elizarov S (2015) Experimental research on the load/unload response ratio (LURR) theory. Earthq Res China 3:31-39

Lu CP, Dou LM, Liu H, Liu HS et al (2012a) Case study on microseismic effect of coal and gas outburst process. Int J Rock Mech Min 53:101-110

Lu CP, Dou LM, Liu BA et al (2012b) Microseismic low-frequency precursor effect of bursting failure of coal and rock. J Appl Geophys 79:55-63

Lu CP, Dou LM, Zhang N et al (2013) Microseismic frequency-spectrum evolutionary rule of rockburst triggered by roof fall. Int J Rock Mech Min 64:6-16

Naiguang G, Ping YU, Mingde D et al (1998) The simulated experimental studies on cause of thermal infrared precursor of earthquakes. Earthquake 18(1):83-88

Planck M (1959) The theory of heat radiation. Dover, New York, USA

Prigogine I (1969) Structure, dissipation and life. Theoretical physics and biology. North-Holland Publishing Company, Amsterdam

Qiang ZJ, Xu XD, Dian CG (1990) Abnormal infrared thermal of satellite-forewarning of earthquakes. Chin Sci Bull 35:1324-1327

Rawat V, Saraf AK, Das J et al (2011) Anomalous land surface temperature and outgoing long-wave radiation observations prior to earthquakes in India and Romania. Nat Hazards 59 (1):33-46

Read MD, Ayling MR, Meredith PG, Murrell SA (1995) Microcracking during triaxial deformation of porous rocks monitored by changes in rock physical properties. Tectonophysics 245(3):223-235

Rudnicki JW, Sternlof KR (2005) Energy release model of compaction band propagation. Geophys Res Lett 32(16):1-4

Saraf AK, Rawat V, Banerjee P et al (2008) Satellite detection of earthquake thermal infrared precursors in Iran. Nat Hazards 47(1):119-135

Schiavi A, Niccolini G, Tarizzo P, Carpinteri A et al (2011a) Acoustic emissions at high and low frequencies during compression tests in brittle materials. Strain 47:105-110

Schiavi A, Niccolini G, Tarizzo P et al (2011b) Waveforms and frequency spectra of elastic emissions due to macrofractures in solids. In: Experimental and applied mechanics, vol 6. Springer, New York, pp 613-621

Schiavi A, Niccolini G, Carpinteri A, Lacidogna G (2013) Damage assessment in Syracuse limestone specimens by frequency analysis of elastic emissions. In: Experimental and applied mechanics, vol 4, pp 105-109

Senseny PE, Hansen FD, Russell JE et al (1992) Mechanical behaviour of rock salt: phenomenology and micromechanisms. Int J Rock Mech Min Sci Geomech Abstr 29:363-378

Shi X, Xu H, Wan Y et al (1994) The rock fracture under simulated tide force-laboratory study on the load/unload response ratio (LURR) theory. Acta Geophys Sin 37:631-636

Wang CL (2014) Identification of early warning key point for rockmass instability using acoustic emission/microseismic activity monitoring. Int J Rock Mech Min Sci 71(10):171-175

Wang CL, Wu AX, Liu XH et al (2009) Study on fractal characteristics of $b$ value with microseismic activity in deep mining. Proc Earth Planet Sci 1(1):592-597

Wasantha PLP, Ranjith PG, Shao SS (2014) Energy monitoring and analysis during deformation of bedded-sandstone: use of acoustic emission. Ultrasonics 54(1):217-226

Wu L, Cui C, Geng N, Wang J (2000) Remote sensing rock mechanics (RSRM) and associated experimental studies. Int J Rock Mech Min Sci 37:879-888 
Wu L, Wu H, Li G (2001) Experimental exploration to thermal infrared imaging for detecting the transient process of solid impact. Chin Sci Bull 46(10):872-877

Wu L, Liu S, Wu Y et al (2006a) Precursors for rock fracturing and failure-part I: IRR image abnormalities. Int J Rock Mech Min Sci 43:473-482

Wu L, Liu S, Wu Y et al (2006b) Precursors for rock fracturing and failure-Part II: IRR T-curve abnormalities. Int J Rock Mech Min Sci 43(3):483-493

Zhang L, Yu H, Yin X (2013) Failure potential evaluation in engineering experiments using load/ unload response ratio method. Pure Appl Geophys 170(1):237-245

Open Access This chapter is licensed under the terms of the Creative Commons Attribution-NonCommercial 4.0 International License (http://creativecommons.org/licenses/by-nc/ 4.0/), which permits any noncommercial use, sharing, adaptation, distribution and reproduction in any medium or format, as long as you give appropriate credit to the original author(s) and the source, provide a link to the Creative Commons license and indicate if changes were made.

The images or other third party material in this book are included in the book's Creative Commons license, unless indicated otherwise in a credit line to the material. If material is not included in the book's Creative Commons license and your intended use is not permitted by statutory regulation or exceeds the permitted use, you will need to obtain permission directly from the copyright holder.

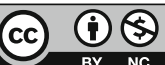

